\title{
Estudiar al máximo para actuar lo mínimo ${ }^{1}$ Study the Maximum to Act as Little as Possible
}

\author{
Jorge Perelli Botello ${ }^{\mathrm{a}}$, Antonio López Sánchez ${ }^{\mathrm{b}}$ \\ ${ }^{a}$ Ingeniero de Caminos, Grupo Retineo, Presidente Ejecutivo \\ ${ }^{b}$ Ingeniero Civil MSc, Retineo Ingeniería, Director General
}

Recibido el 14 de octubre de 2020; aceptado el 24 de marzo de 2021

\section{RESUMEN}

Este artículo es una reflexión sobre cómo plantear una correcta filosofía de actuación en las obras de rehabilitación estructural, que se puede resumir en el siguiente lema: "estudiar al máximo para actuar lo mínimo", promovida por nuestro querido compañero Luis $\mathrm{M}^{\mathrm{a}}$ Ortega Basagoiti. La reflexión se realiza desde la experiencia obtenida en el desarrollo de trabajos, en el campo de la rehabilitación estructural, de más de 30 años del equipo técnico de Retineo. Y ello es porque habitualmente se invierte de manera escasa en los estudios previos, lo que provoca muchas desviaciones en las obras y en especial en las de rehabilitación estructural. Nuestra filosofía de trabajo parte de un planteamiento a la inversa: realizar un exhaustivo análisis inicial para que las soluciones definidas sean las óptimas y las desviaciones técnicas y económicas las mínimas.

PALABRAS ClAVE: Estudios previos, metodología, rehabilitación estructural, reparación, refuerzo, durabilidad.

(C) 2021 Asociación Española de Ingeniería Estructural (ACHE). Publicado por Cinter Divulgación Técnica S.L. Todos los derechos reservados.

\begin{abstract}
This article is a reflection on the correct philosophy of action in structural rehabilitation works which can be summarized in the following motto: "study to the maximum to act as little as possible", promoted by our dear colleague Luis $\mathrm{M}^{\mathrm{a}}$ Ortega Basagoiti. The reflection is made from more than 30 years of Retineo technical team experience in the field of structural rehabilitation. And this is because usually little investment is made in previous studies, which causes many deviations in the works and especially in those of structural rehabilitation. Our work philosophy is based on an inverse approach: carry out a thorough initial analysis so that the solutions defined are the optimal ones and the technical and economic deviations the minimum.
\end{abstract}

KEYWORDS: Previous studies, methodology, structural rehabilitation, repair, reinforcement, durability.

(c) 2021 Asociación Española de Ingeniería Estructural (ACHE). Published by Cinter Divulgación Técnica S.L. All rights reserved.

1.

\section{INTRODUCCIÓN}

Pese a que teóricamente se está proyectando la mayoría de las estructuras para una vida útil de entre 50 y 100 años (EHE Artículo $5[1]$ ), un número no despreciable suelen presentar deterioros importantes debidos, entre otros, a procesos de corrosión de armaduras o procesos de tipo expansivo por ataques químicos, a edades muy inferiores a esa vida útil de proyecto. Ello exige con alta frecuencia intervenciones cuyo importe su-

* Persona de contacto / Corresponding author:

Correo-e / email: alopez@retineo.es (Antonio López Sánchez). pera con creces lo que debería inscribirse en un mantenimiento o conservación normal.

Además, la experiencia de los últimos 40-50 años ha demostrado que la durabilidad de la mayoría de esas reparaciones es, a su vez, relativamente reducida, siendo necesario repetir las mismas a los 8 o 10 años, fundamentalmente debido a que el diagnóstico del proceso de daño tiene importantes limitaciones, tanto a la hora de determinar el proceso patológico en detalle como sobre todo a la de cuantificar con precisión el área afectada a reparar.

1.- Esta frase tiene su origen en una ponencia que realizó nuestro compañero Luis Ortega Basagoiti en Cuba sobre evaluación de estructuras deterioradas en el año 1998. 


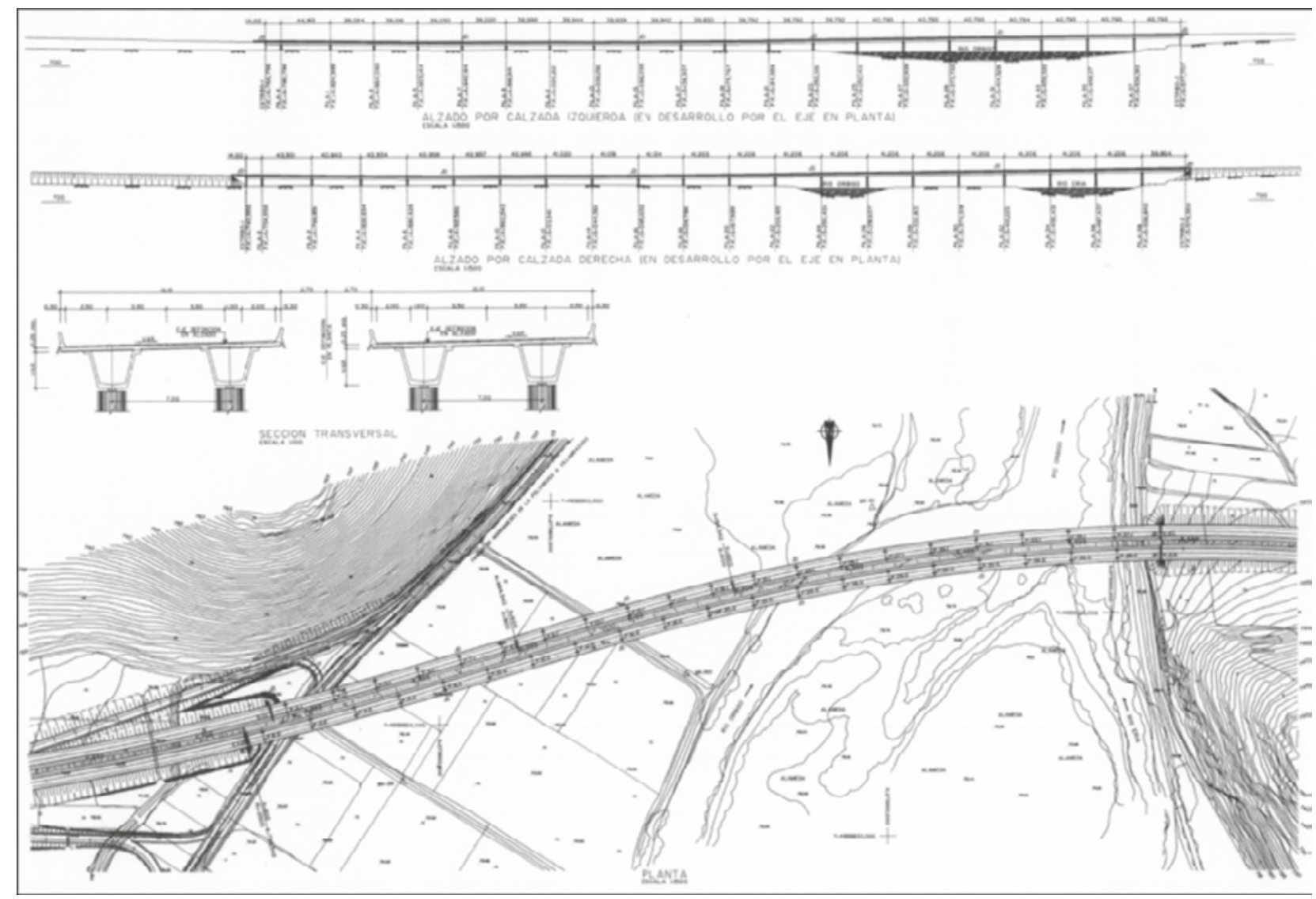

Figura 1. Definición de la estructura.

En la línea de lo expuesto, existe una queja generalizada por parte de los administradores de infraestructuras por la escasa durabilidad de las actuaciones de reparación y los incrementos de costes en las obras de rehabilitación estructural.

Lamentablemente, es habitual un modelo de actuación cortoplacista que se basa en la realización de estudios y proyectos con pocos recursos, que no pueden profundizar el origen del proceso patológico y aportan soluciones no ajustadas a las necesidades reales, siendo necesario "resolver" en obra muchas cuestiones técnicas.

Esta forma de actuar es claramente perniciosa técnica y económicamente, por lo que debería cambiarse al analizar rehabilitaciones de obras existentes afectadas por daños de todo tipo. El proceso correcto, en nuestra opinión, debería ser el siguiente:

- Identificación de la naturaleza de los daños (diagnóstico tradicional).

- Evaluación de la importancia de esos daños, su trascendencia y su evolución.

- Establecimiento de la necesidad o no de intervención sobre la base de criterios funcionales o de seguridad y de la prognosis de evolución futura.

- Estudio de las posibles alternativas de intervención, tanto desde el punto de vista técnico como económico, considerando el ciclo total de vida de la estructura.

- Redacción del proyecto de intervención.

- Ejecución de la obra con un control adecuado, preferentemente incluyendo instrumentación.

- Establecimiento de un plan de mantenimiento.
Para poder llevar a cabo este planteamiento, en el ámbito de la rehabilitación estructural, es necesario conseguir la máxima trazabilidad y calidad del trabajo en todas sus fases: inspección técnica, caracterización de materiales y estructural, análisis y diagnóstico, estudio de soluciones y ejecución de la obra, complementado con el control y seguimiento mediante instrumentación. En los procesos patológicos estructurales es muy importante integrar todas las fases de actuación de cara a tener éxito en la intervención. Por tanto, se necesita una perfecta trazabilidad entre las etapas, lo que posibilita un control en todo el proceso, garantizando el éxito a un coste competitivo.

Los estudios técnicos (materiales, humedades, geotécnicos, estructurales y peritajes) son fundamentales en toda intervención. Así, en las construcciones tradicionales se producen con cierta frecuencia alteraciones de los materiales estructurales por diversos procesos patológicos (humedades, ataques por los agentes climáticos, erosiones) y se debe efectuar un análisis desde el punto de vista de la durabilidad y la compatibilidad con otros materiales, así como el estudio de tratamientos de reparación. En otras ocasiones, el objeto es determinar el cumplimiento de las exigencias básicas de seguridad estructural a partir de las características resistentes reales de los materiales y las acciones normativas.

Por otra parte, es importante integrar en estos trabajos las técnicas de instrumentación estructural para la medición de determinados parámetros o características de las estructuras. La monitorización, automática o manual, es una técnica que permite conocer la calidad, estado de los materiales y procesos de deterioro, así como analizar el comportamiento estructural de una construcción. También, dependiendo de los casos, es 

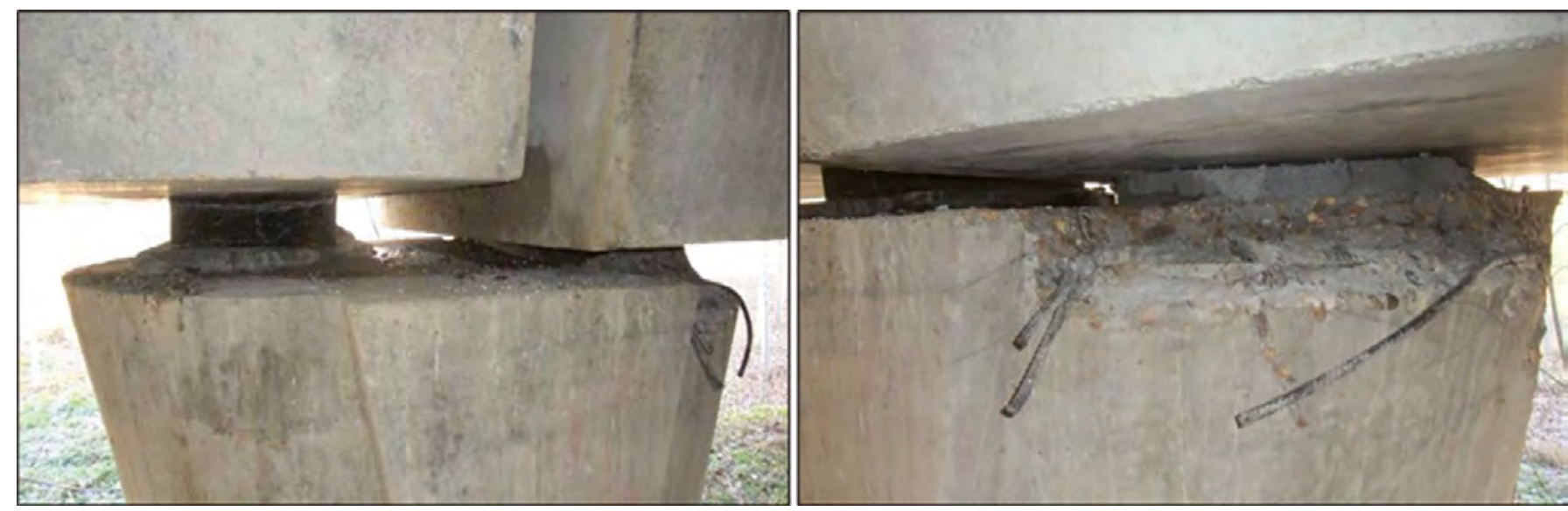

Figura 2. Izquierda: reptado y caída de un apoyo en el puente del ejemplo 1; derecha: rotura provocada en la coronación de la pila.
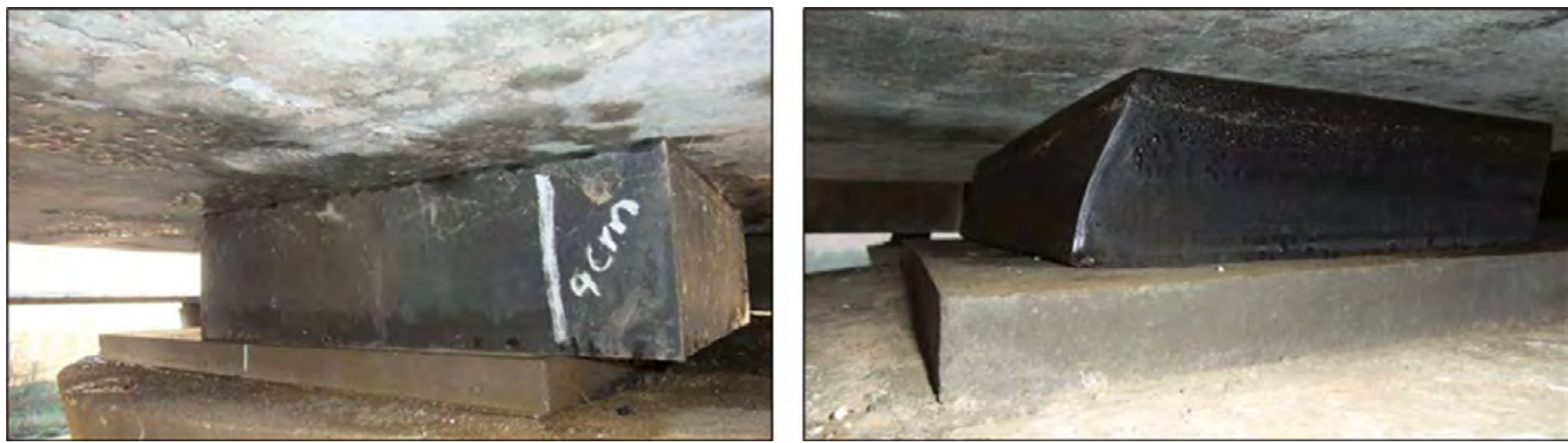

Figura 3. Izquierda: aparente reptado lateral de un apoyo en el puente del ejemplo 1; derecha: deformación en sentido longitudinal de un apoyo en el puente del ejemplo 1 .

importante efectuar ensayos de auscultación estructural (medidas de vibraciones, ultrasonidos, termografía...).

Cuando las circunstancias lo requieren, en el ámbito de la filosofía de trabajo señalada, se deben diseñar nuevos procedimientos para corregir defectos que se han observado.

En los puntos siguientes se muestran dos ejemplos, totalmente distintos, donde se ha aplicado esta metodología de trabajo, existiendo una máxima en ellos: cuanto mejor se estudia menos agresiva es la actuación y, por tanto, más eficiente.

\section{2.}

\section{EJEMPLO 1. ROTURA Y CAÍDA DE UN APARATO DE APOYO DE UNA ESTRUCTURA DE UNA AUTOVÍA DE CASTILLA Y LEÓN}

Este ejemplo trata de un doble viaducto de vigas pretensadas prefabricadas en artesa, cada uno de los cuales tiene 21 vanos isostáticos con luces variables del orden de los $40 \mathrm{~m}$, con una rasante sensiblemente horizontal y con juntas de dilatación cada 4 o 5 vanos (figura 1 ).

El día 12 de julio de 2013, a las 21:30 horas, se detectó la expulsión del neopreno de apoyo de una de las vigas sobre la sexta pila, quedando apoyada sobre el mortero de nivelación, parcialmente inclinada unos grados. La incidencia afectó al carril lento, que fue cortado, produciéndose una irregularidad en el firme del carril con un desnivel respecto a la rasante en torno a $\operatorname{los} 12 \mathrm{~cm}$.

En la inspección realizada a posteriori se comprobó el reptado y caída de un neopreno con el consiguiente descenso del extremo de la viga afectada y los desperfectos asociados en el propio tablero, al no existir en esa pila junta de dilatación (figura 2). En este caso, el examen de los restantes apoyos mostró que en una serie de casos se observaban neoprenos aparentemente reptados, volando lateralmente por fuera de las camas de nivelación (figura 3).

En general, el reptado o desplazamiento por deslizamiento de los apoyos elastoméricos en puentes, pese a ser conocido desde hace tiempo, lejos de haber sido solucionado parece presentarse, en los últimos tiempos, cada vez con más frecuencia.

El fenómeno a nivel teórico parece claro: el deslizamiento se produce cuando la fuerza horizontal que solicita al apoyo es mayor que la fuerza de rozamiento entre el apoyo y sus contactos superior e inferior. Sin embargo, en la realidad existen numerosas variables que inciden en este proceso $\mathrm{y}$, a juzgar por la frecuencia con la que se sigue produciendo, parece que o no se sabe cuantificar a ciencia cierta cuándo y por qué se producirá el reptado de uno o varios apoyos o no se logra concienciar a los agentes que intervienen en el proyecto, construcción y mantenimiento para cuidar aquellos detalles y circunstancias que pueden dar lugar a este proceso patológico.

Cuando se produce el reptado y el deslizamiento, es necesario actuar para devolver el apoyo a su posición correcta y 
evitar males mayores, como los que se pueden ocasionar si se produce la caída del mismo, como en este caso. En este sentido, en [2] se subraya que la operación de sustitución de un apoyo con relación al coste de suministro del mismo puede situarse en una relación del orden de 50 a 1 o incluso superar con creces esa proporción.

Volviendo al ejemplo, durante la fase de estudio, en la inspección técnica, se comprobó la situación de las camas de asiento inferiores respecto a las pilas y de los apoyos respecto a las vigas, lo que permitió concluir que esos aparentes reptados laterales no eran tales, sino muy posiblemente problemas derivados de posibles errores de replanteo durante la construcción acompañados de decisiones poco afortunadas, pues las camas de asiento estaban sensiblemente centradas en las pilas y los neoprenos sensiblemente bien centrados con los ejes de las vigas, presentando, sin embargo, vuelos laterales como los apreciados en la figura 3. El examen cuidadoso de la posición del eje de la viga respecto al eje de la pila confirmaba esta hipótesis. En el análisis estructural se verificaron las pilas con la excentricidad accidental y se comprobó que, aunque los coeficientes de seguridad disminuyeron, se mantenían en valores admisibles. En todo caso, esta circunstancia obligó, como se comenta más adelante, al levantamiento de tableros y recrecido lateral de camas de nivelación en bastantes líneas de apoyo para lograr un asiento correcto de los neoprenos.

El apoyo reptado y caído (en sentido longitudinal) se debió a un error puntual de colocación de ese neopreno, girado $90^{\circ}$ respecto a su posición teórica, junto a la descompensación de cargas en la línea de apoyos.

Un aspecto fundamental del estudio fue realizar un análisis de la situación actual de la estructura para valorar las consecuencias de la pérdida del aparato de apoyo. Para ello se consideró la isostaticidad de las vigas (son vigas biapoyadas), lo que hacía que un proceso de descenso de uno de sus apoyos no se tradujera en esfuerzos significativos en la viga (esta, de no estar unida a la otra viga del tablero por la losa de compresión, se limitaría a girar sin sufrir esfuerzo alguno). Pero al estar conectadas ambas vigas por la losa de compresión, el que uno de los extremos de una de ellas descienda por la pérdida del apoyo implica unos movimientos considerables y, como consecuencia, puede inducir unos notables esfuerzos en el elemento que conecta ambas vigas, es decir, la losa de compresión.

Para valorar de forma cuantitativa la estructura afectada se realizó un modelo partiendo de la inercia bruta en todas las barras (se desarrolló un modelo simplificado de la estructura mediante un emparrillado de 5 barras longitudinales y 21 transversales, considerándose la excentricidad de las barras al no coincidir los baricentros de las secciones transversales). Se supuso, como única carga, la actuación de una fuerza puntual descendente, aplicada en el punto donde estaba el apoyo y equivalente a la reacción estimada en el mismo (1934.5 kN). En realidad, este sería el estado de carga que, superpuesto al del peso propio y la carga permanente actuando sobre el emparrillado con los cuatro apoyos, llevaría a la situación actual del tablero. No se han considerado, en este primer análisis, los efectos térmicos cíclicos y las deformaciones impuestas por retracción y fluencia (la estructura tenía una edad superior a los 15 años). Hay que tener en cuenta que el objetivo era valorar las consecuencias de la pérdida del aparato de apoyo.
El esquema de cálculo seguido ha sido iterativo, partiendo en todas las barras de la rigidez (EI) correspondiente a la inercia bruta y sustituyendo esta por la inercia fisurada en aquellas barras en las que se obtuviese un flector superior al momento de fisuración teóricamente resistido por la misma, además se tuvo en cuenta la deformación por cortante de la losa. En este caso, también con tan solo tres iteraciones, se llega a una situación en que la estructura así considerada presenta un descenso de $11 \mathrm{~cm}$ en el nudo en el que debía haber estado el apoyo perdido, prácticamente coincidente con los $12 \mathrm{~cm}$ medidos.

Respecto al análisis cabe señalar lo siguiente:

- Las deformaciones estimadas para ambas vigas en este modelo se ajustan a las realmente inducidas por el proceso de pérdida del apoyo, al no incluir deformaciones por peso propio y cargas permanentes.

- Los posibles daños en las dos zonas longitudinales de contacto o apoyo de la losa de compresión sobre los bordes internos de las dos vigas artesa se producirían por rotura del hormigón.

- Las pilas no se han visto afectadas por la excentricidad de cargas.

De acuerdo con todo lo expuesto, la actuación contempló una intervención que se resume a continuación:

1. Demolición del pavimento a $2 \mathrm{~m}$ a cada lado del eje de pila.

2. Demolición del pavimento sobre la zona de losa situada encima de los bordes interiores de ambas vigas. Además, en el caso de la viga derecha, demolición de la prelosa por la cara inferior, junto al borde interior de la viga artesa en una longitud de unos $6 \mathrm{~m}$, para observar la presencia de posibles daños, por momentos positivos, en la cara inferior de la losa.

3. Examen del estado de la losa. Se comprobó que no existían armaduras rotas, aunque sí daños en el hormigón. Ver figuras 4 y 5.

4. Movilización del tablero para colocar un nuevo aparato de apoyo. El trabajo se realizó con una central hidráulica sincronizada que permite el control en cargadesplazamiento (ver figura 6).

5. Reposición del hormigón de la losa de compresión y del aglomerado. Ver figuras 7 y 8.

6. Movilización del tablero para equilibrar cargas y recolocar los aparatos de apoyo detectados en la inspección técnica (ver figura 3). En las figuras 9 y 10 se muestran distintas situaciones de la operación. Comentar que esta operación se realizó con tráfico rodado y sin limitación de velocidad.

\section{3. \\ EJEMPLO 2. CONSOLIDACIÓN DE UNA TORRE MUDÉJAR EN LA COMUNIDAD DE MADRID.}

Este ejemplo se corresponde con una actuación en una construcción declarada de Bien de Interés Cultural como Zona Arqueológica, desde el 18-10-1988 (BOE, 27-12-88). Se trata de una torre fortaleza. Las primeras noticias sobre ella se remontan al año 929 (308 de la Hégira musulmana), año en el que lbn'ldari relata que el gobernador de Guadalajara vence a una expedición leonesa que atacó Guadalajara después de devastar 


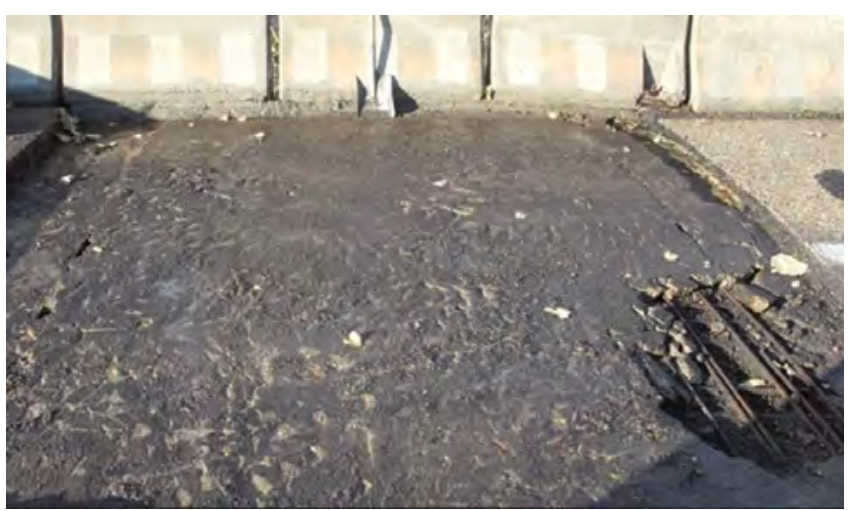

Figura 4. Demolición del pavimento en la zona afectada. Pueden observarse roturas de la losa de compresión.

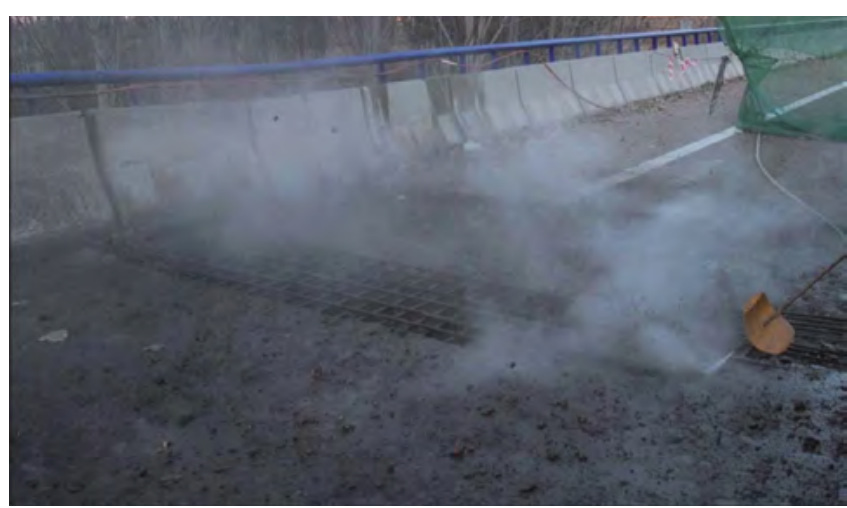

Figura 5. Demolición del hormigón deteriorado de la losa de compresión por hidrodemolición.
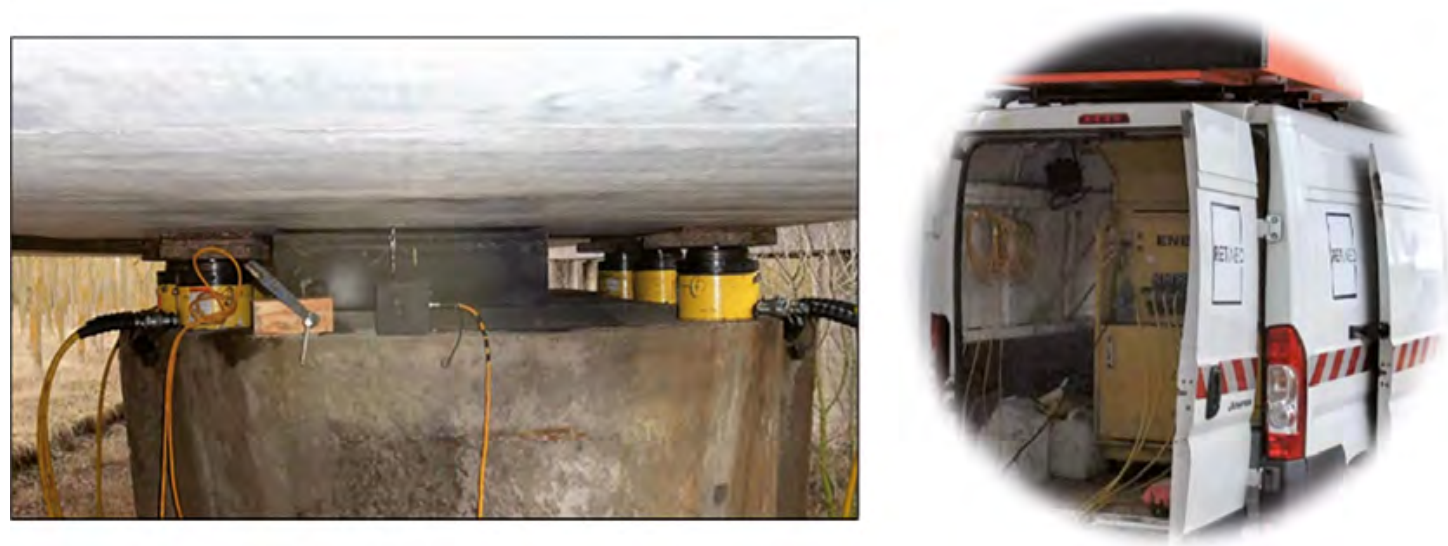

Figura 6. Gatos hidráulicos bajo el tablero.

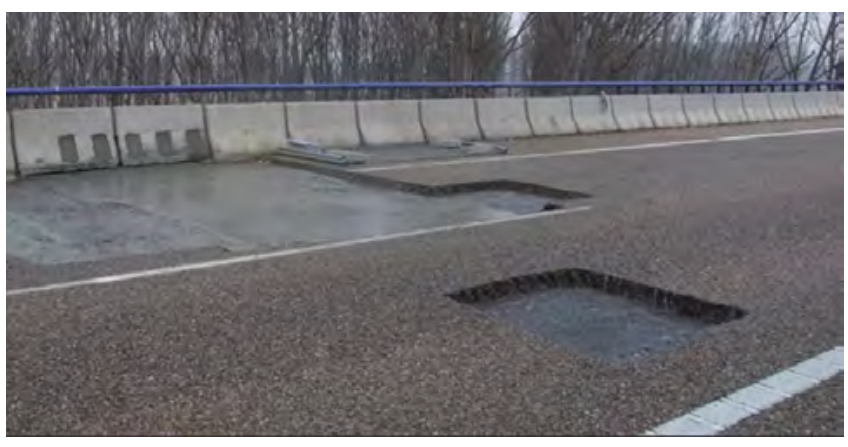

Figura 7. Reposición del hormigón deteriorado de la losa de compresión.

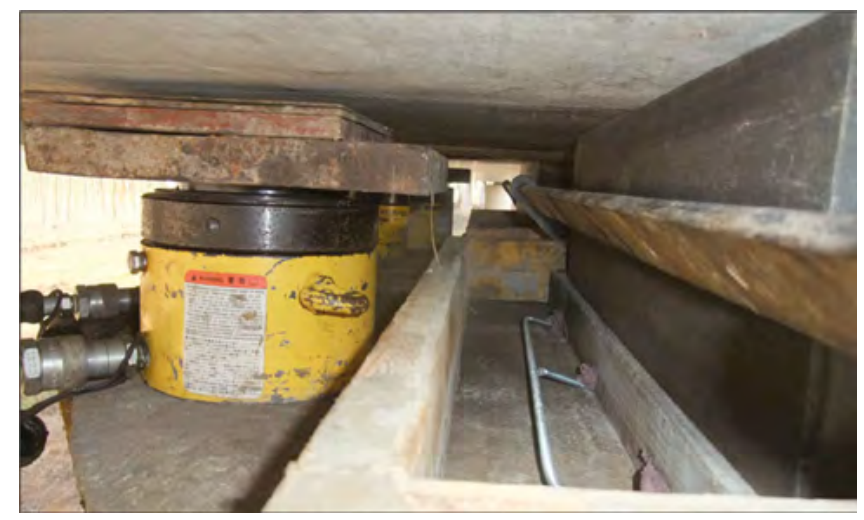

Figura 9. Recrecido de camas de asiento y recolocación de apoyos.

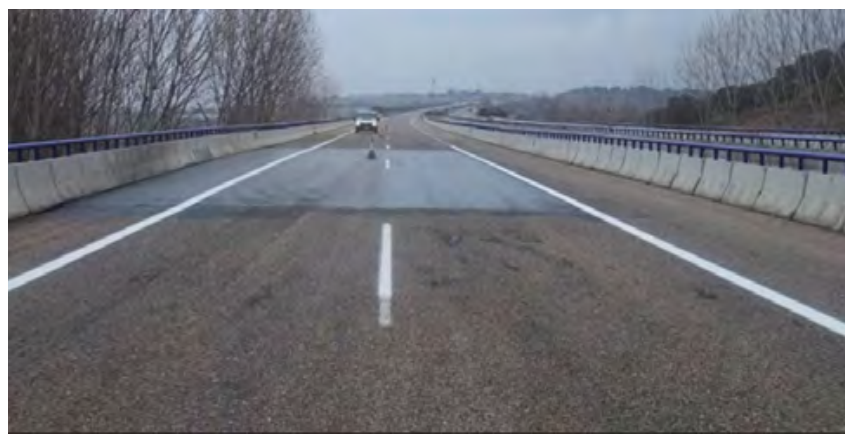

Figura 8. Reposición del aglomerado.

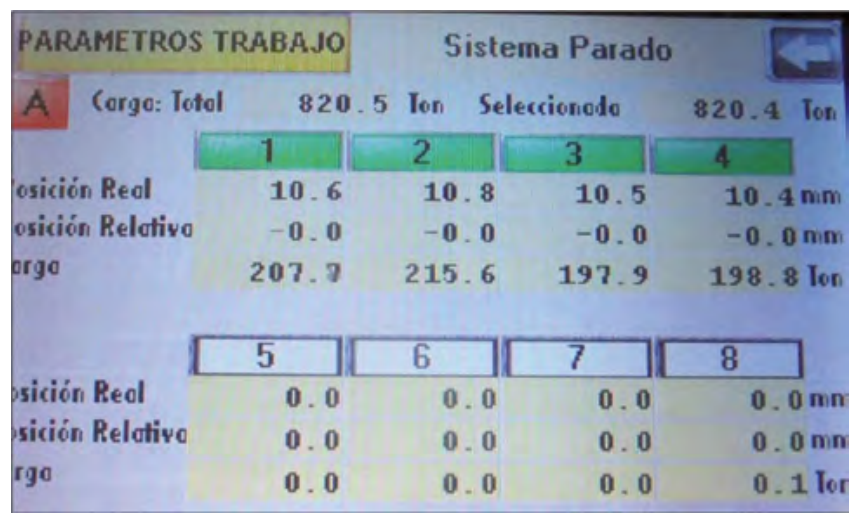

Figura 10. Central hidráulica sincronizada. Equilibrado de cargas (canal 1 y 2 pertenecen a una vano y canal 3 y 4 a otro). 


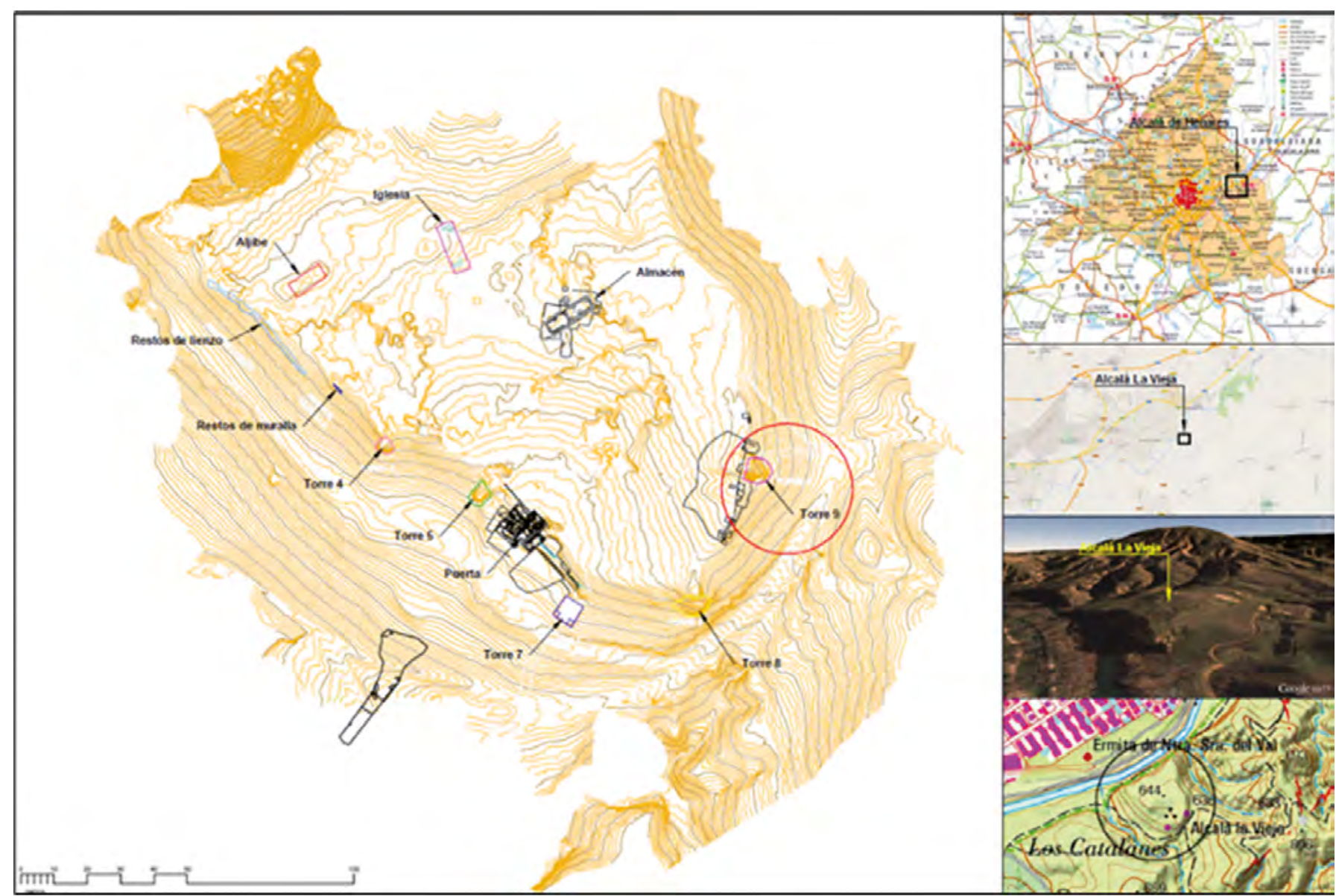

Figura 11. Ubicación de la torre.

la fortaleza islámica de Ai-Qal'aya, que Levi Prove identifica con la de Alcalá (figura 11).

Su estado de conservación era muy deficiente hasta el punto de que en el año 2014 se decidió su vallado perimetral para proteger la estructura y a los propios visitantes ante posibles derrumbes (figura 12).

La torre en esa fecha, desde un punto de vista estructural, era un bloque de forma irregular formado por dos tipologías constructivas (mampostería y tapial de tierra apisonada) que no se podía considerar como un sólido rígido. En la figura 13 se muestra la configuración de la misma.

El monumento presentaba importantes procesos patológicos manifestados en forma de grietas, desprendimientos y degradación del material, motivados por acción de la lluvia, las variaciones térmicas y el viento, que generaron importantes daños que ponían en riesgo la integridad del bloque de tapial. Incluso, de no actuar de manera rápida, el proceso de erosión seguiría avanzando pudiendo llegar a producir el colapso parcial de la torre.

Para poder abordar la consolidación de la torre, en esta situación crítica y con unos recursos limitados, se planteó la actuación por fases, donde se ha efectuado un estudio de deta1le para minimizar la intervención, control de todo el proceso con un sistema de instrumentación y ejecución con técnicas antiguas y modernas. Así, se establecieron las siguientes fases:

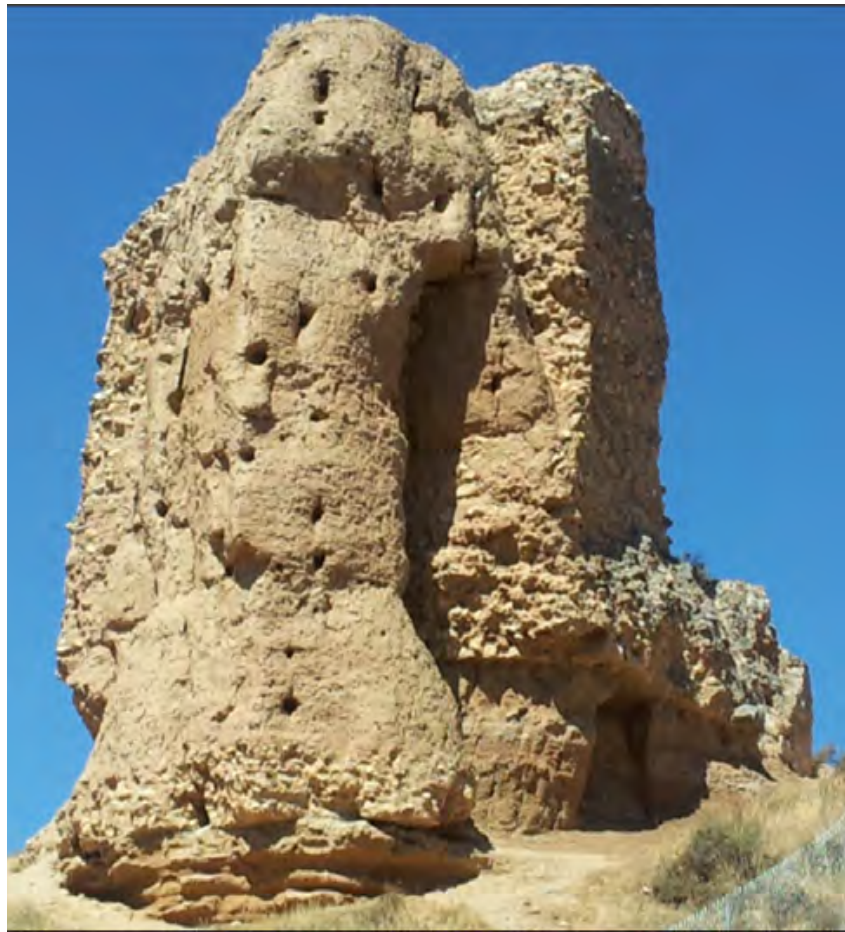

Figura 12. Estado de la torre en el año 2014. 


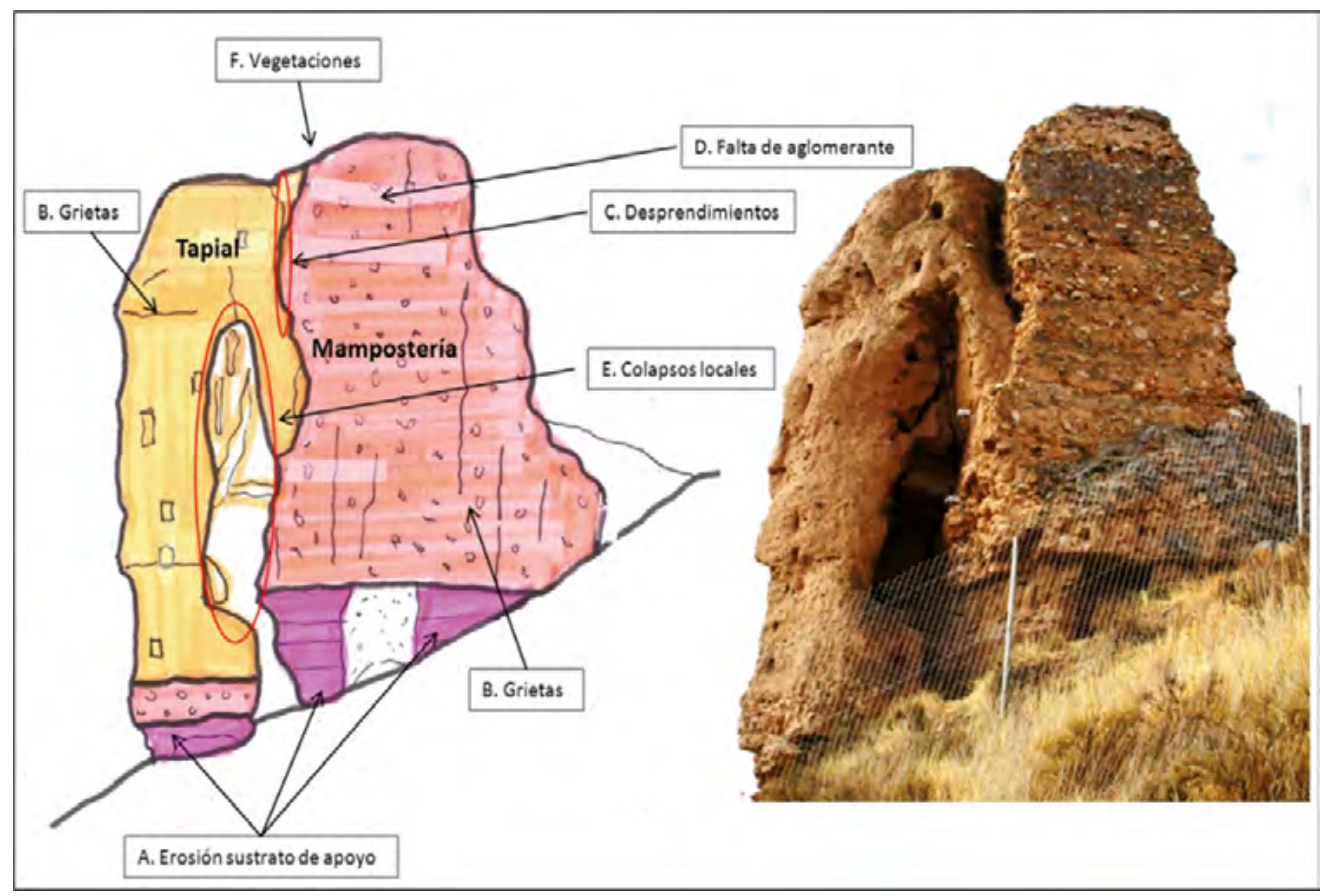

Figura 13. Configuración de la torre en el año 2014. Lienzo sur-este.

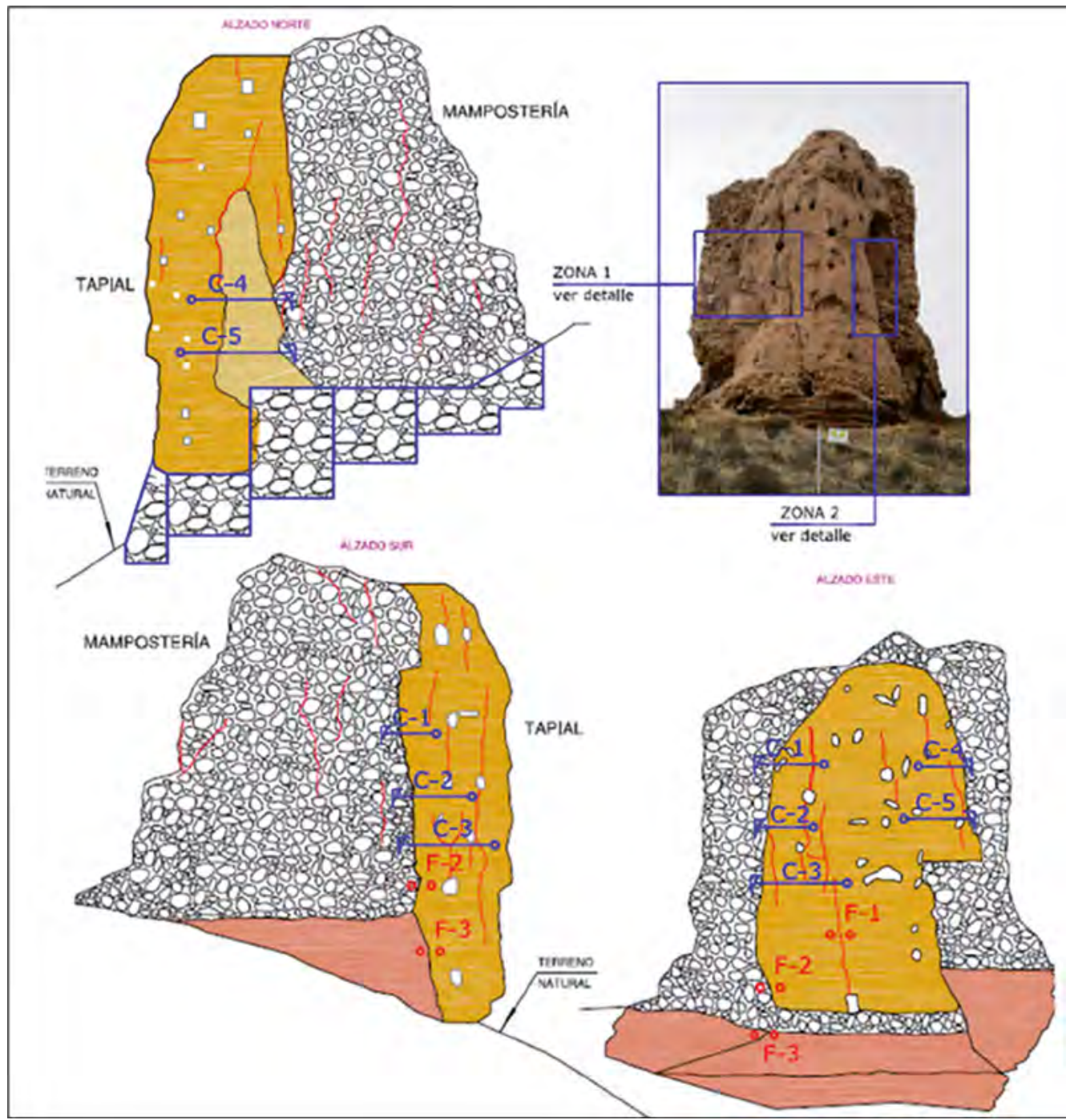

Figura 14. Instrumentación dispuesta en la torre. 


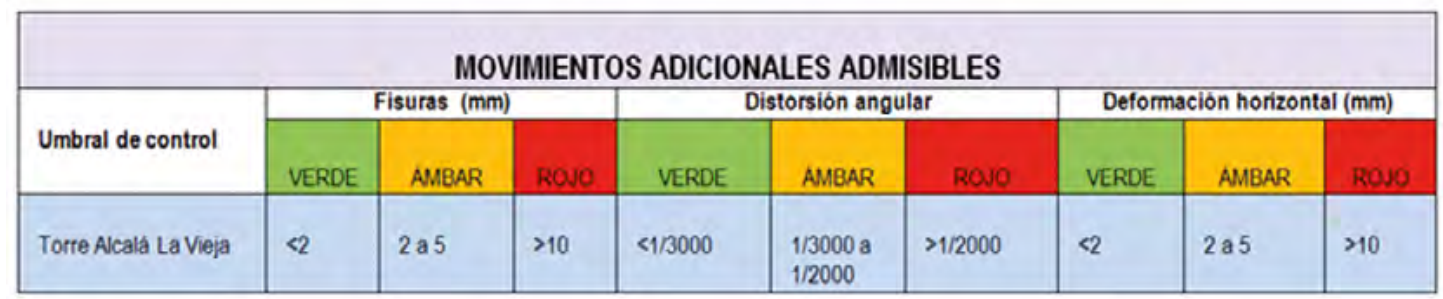

\begin{tabular}{|l|}
\hline MEDIDAS A TOMAR \\
\hline No son necesarias. \\
\hline Control exhaustivo de la instrumentación. \\
Precaución en los trabajos. \\
Parada de los trabajos. \\
Necesidad de actuaciones de emergencia. \\
\hline
\end{tabular}

Figura 15. Umbrales de riesgo.

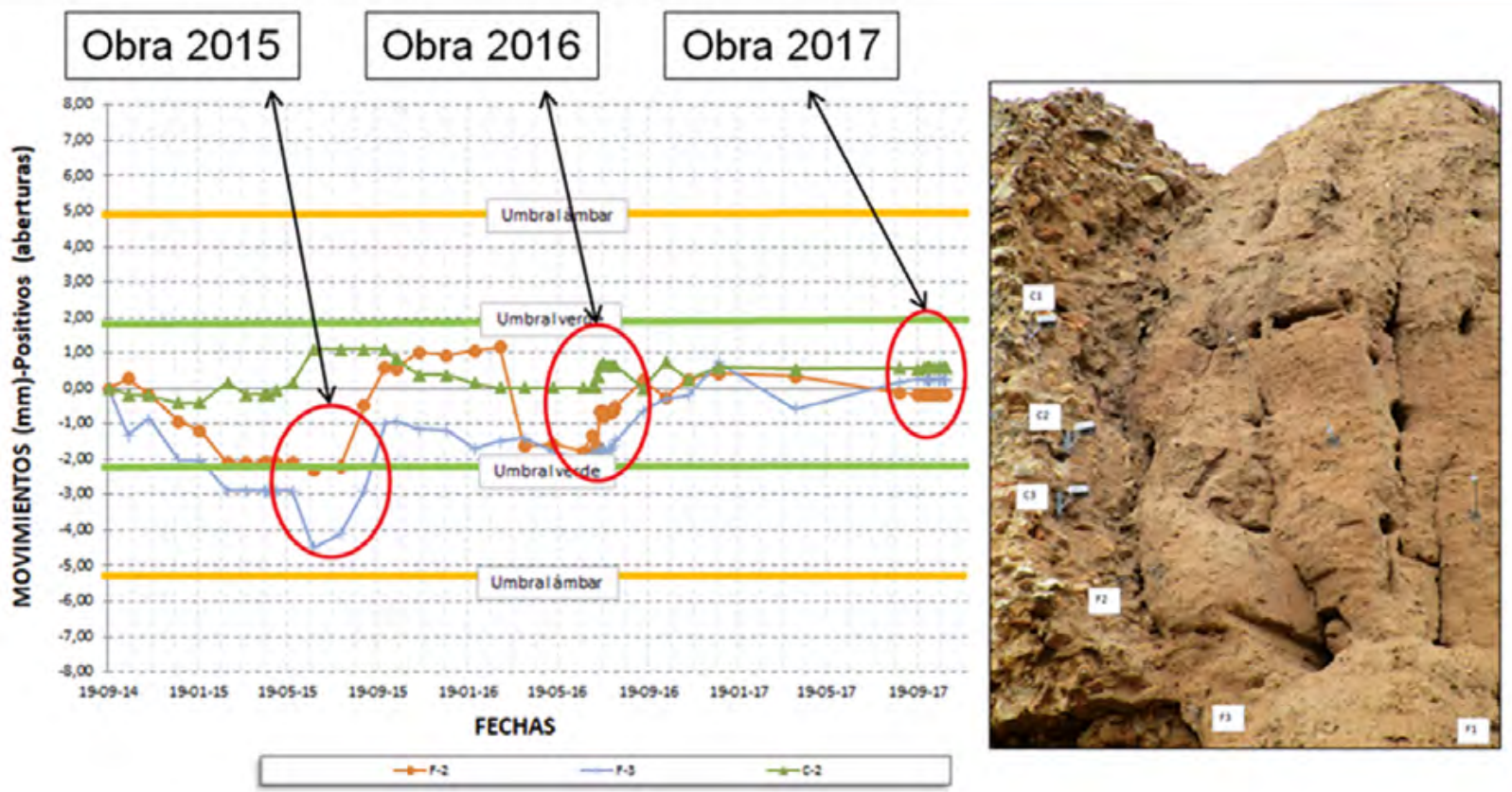

Figura 16. Seguimiento de la instrumentación (2014-2017).

\section{Fase $1^{a}$. Instrumentación}

En el año 2014 se instaló una instrumentación con objeto de controlar la evolución de las fisuras y deformaciones de la torre en su conjunto. Esta instrumentación se diseñó con un doble objetivo: por un lado, proporcionar un marco de seguridad para la ejecución de los trabajos de consolidación y, por otro, verificar la correcta ejecución de los trabajos al constatar la estabilización de la torre.

Así, la instrumentación dispuesta consistió en la instalación de los siguientes sensores:

- Control de movimientos de fisuras.

- Control de movimientos de convergencias.

- Control de las condiciones ambientales.
El control de las fisuras a instrumentar se efectúo mediante la colocación de puntos de extensometría a ambos lados de cada fisura. La realización de medidas se llevó a cabo con extensómetro mecánico de rango $200 \mathrm{~mm}$ y apreciación $0.001 \mathrm{~mm}$. En caso de que los movimientos excedieran del rango del extensómetro, el control se realizaría mediante un calibre digital de alta precisión de rango $300 \mathrm{~mm}$ y apreciación $0.01 \mathrm{~mm}$. El control de convergencias se realizó mediante un reloj comparador analógico de rango $30 \mathrm{~mm}$ y apreciación $0.01 \mathrm{~mm}$. En la figura 14 se muestra la ubicación de las referencias.

La instrumentación se evaluó con la metodología de los umbrales de riesgo. Para facilitar la identificación del nivel de seguridad en el que se encontraban los valores alcanzados, se estableció un código de colores de tipo semafórico: verde, ámbar y rojo, de menor a mayor riesgo. 


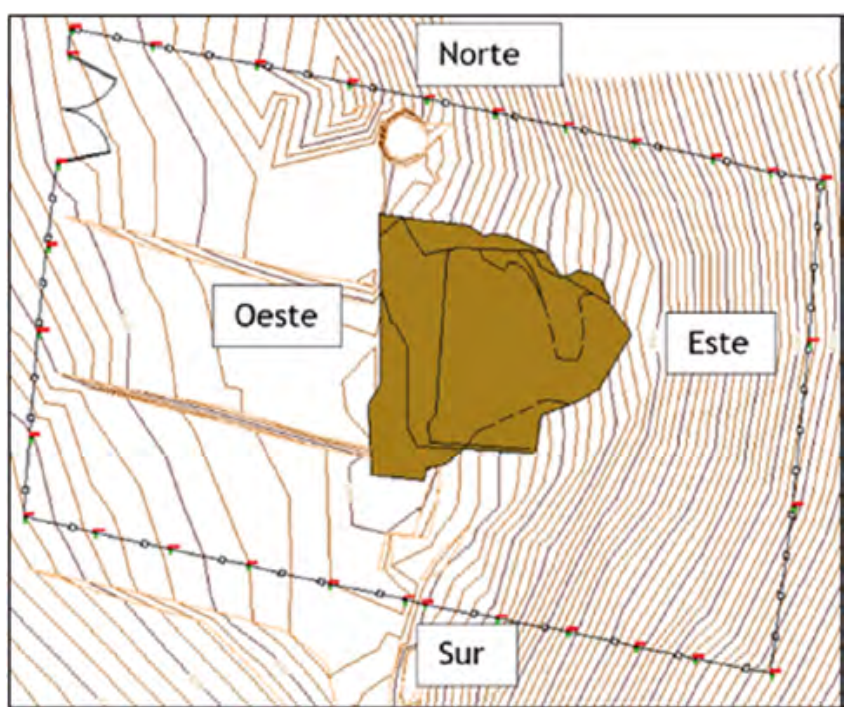

Figura 17. Topografía.

En la figura 15 se recogen valores habitualmente aceptados $[3,4,5,6,7]$ como umbrales admisibles para el control de abertura de fisuras (en $\mathrm{mm}$ ) y para el control de movimientos relativos mediante convergencias (en $\mathrm{mm}$ ) en este tipo de construcciones.

En la figura 16 se muestra el control llevado a cabo durante toda la intervención, que se comenta en las fases siguientes. Como se puede apreciar, durante la actuación de consolidación de la cimentación (año 2015) se superó el umbral verde y se tuvo que modificar la secuencia de ejecución de los bataches (ver figura 28) para corregir la situación.
Fase $2^{a}$. Estudio y diseño de la consolidación estructural

Esta fue la fase más importante de toda la intervención. El estudio contempló las siguientes tareas:

- Inventario de los procesos patológicos. En primer lugar, se realizó un levantamiento topográfico de la ladera y de la torre. En la figura 17 se muestra la planta donde se puede apreciar la fuerte pendiente donde se ubica la Torre.

Sobre estos planos se realizó una inspección de detalle para inventariar los procesos patológicos, localizando y cuantificando los daños. Con el resultado se elaboraron los planos de daños que recogían la incidencia y la naturaleza por zonas.

El inventario realizado consistió en localizar y cuantificar los siguientes tipos de daños (ver figura 18):

- Erosión del sustrato de apoyo.

- Grietas.

- Desprendimientos.

- Falta de aglomerante.

- Colapsos locales.

- Presencia de vegetación.

- Caracterización geotécnica. Se efectúo una caracterización de la cimentación para determinar el nivel de apoyo de los macizos, resultando que la torre se apoyaba sobre un sustrato de arcilla limosa de color marrón de consistencia dura, sustrato que, de acuerdo con el estudio geotécnico, resistía una tensión admisible de $0.3 \mathrm{~N} / \mathrm{mm}^{2}$. Ver figura 19.

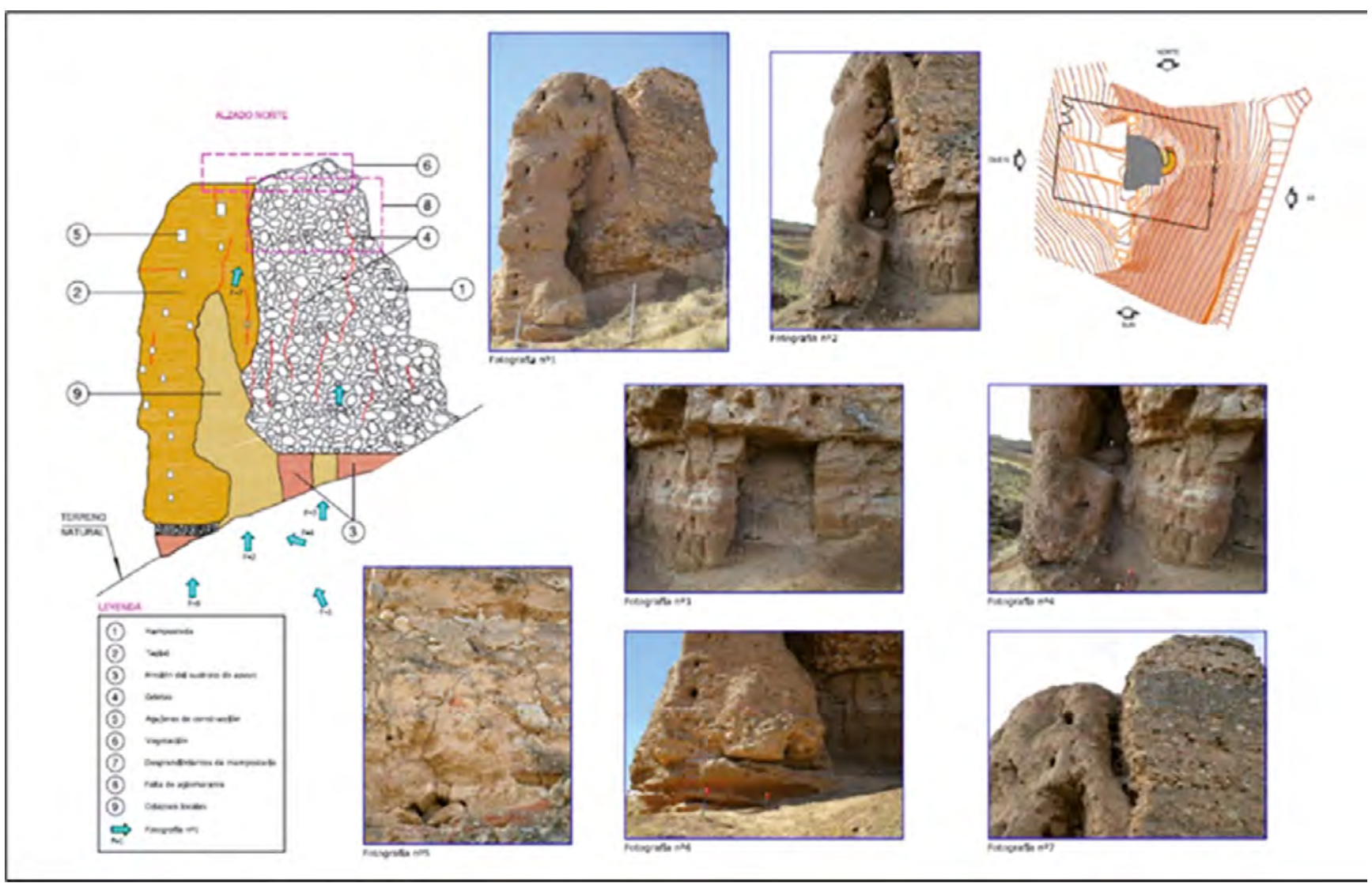

Figura 18. Inventario de daños. 


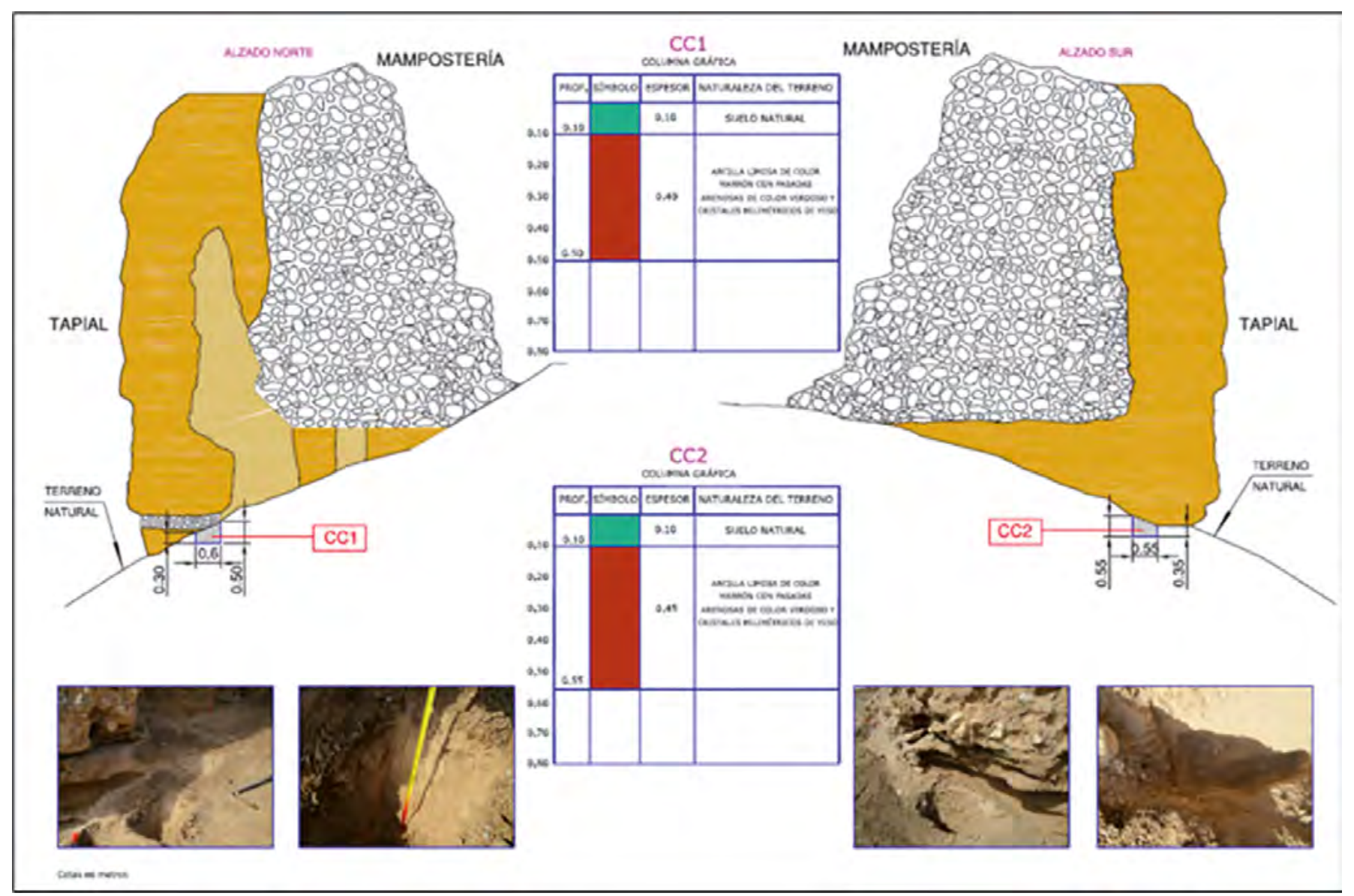

Figura 19. Caracterización geotécnica.

Estos resultados permitieron afirmar que la torre, una vez realizado el recalce, se quedaría apoyada en un nivel que se corresponde con las arcillas marrones de consistencia dura y de alta plasticidad, terreno que tiene unas características geotécnicas adecuadas para cimentar.

- Caracterización del tapial. Los huecos del bloque de tapial presentan profundidades muy variables (desde unos pocos centímetros hasta casi ciento cincuenta centímetros) (figura 20). La existencia de estos huecos puede estar relacionada con los travesaños de madera para configurar el encofrado del tapial de tierra [8].

De cara a la definición de los materiales a emplear en la consolidación del tapial de tierra prensada se realizó una serie de ensayos (resistencia a tracción de anclaje químico) con los siguientes tipos de productos:

- Ensayo E-1. Mortero de cal.

- Ensayo E-2. Resina epoxi.

- Ensayo E-3. Resina acrílica + mortero de cal.

- Ensayo E-4. Resina acrílica + resina epoxi.

En las imágenes 21 a 24 se puede observar el bulbo generado después de arrancamiento.

Como se puede apreciar en las figuras 21 a 24, el hecho de utilizar una resina acrílica como consolidante previo del tapial es eficaz, consiguiendo un incremento sensible del bulbo de anclaje y por tanto de la resistencia. Las cargas de arrancamiento fueron bajas en todos los anclajes; los mejores resultados se obtuvieron en los ensayos E-3 y E-4 (en torno a $0.4 \mathrm{kN})$.

- Análisis estructural. Para realizar el análisis estructural de la torre se partió de las siguientes hipótesis básicas:

- Recalzar la cimentación de la torre. Tal y como se indicaba en la caracterización geotécnica, la torre está asentada sobre un terreno competente. No obstante, existían zonas donde la erosión degradó el sustrato de apoyo y la torre se encontraba parcialmente descalzada.

- De acuerdo con las estimaciones de pesos de la torre, la tensión media transmitida al terreno era inferior a 0.2 $\mathrm{N} / \mathrm{mm} 2$, valor inferior al considerado como admisible en el citado informe geotécnico $\left(0.3 \mathrm{~N} / \mathrm{mm}^{2}\right)$.

- Una vez realizado el recalce según se indica más adelante, se pudo considerar que la base de la torre es una zona estable, por lo que el riesgo de colapso quedaría entonces limitado a un giro o desplazamiento de la misma alrededor de esta zona, produciéndose una rotura o colapso previsible del lienzo sur-este (ver figura 13).

La consolidación estructural de la torre se planteó con la técnica de anclajes encapsulados de fijación interna. El objetivo era evitar que se pudieran producir movimientos (giros o des- 

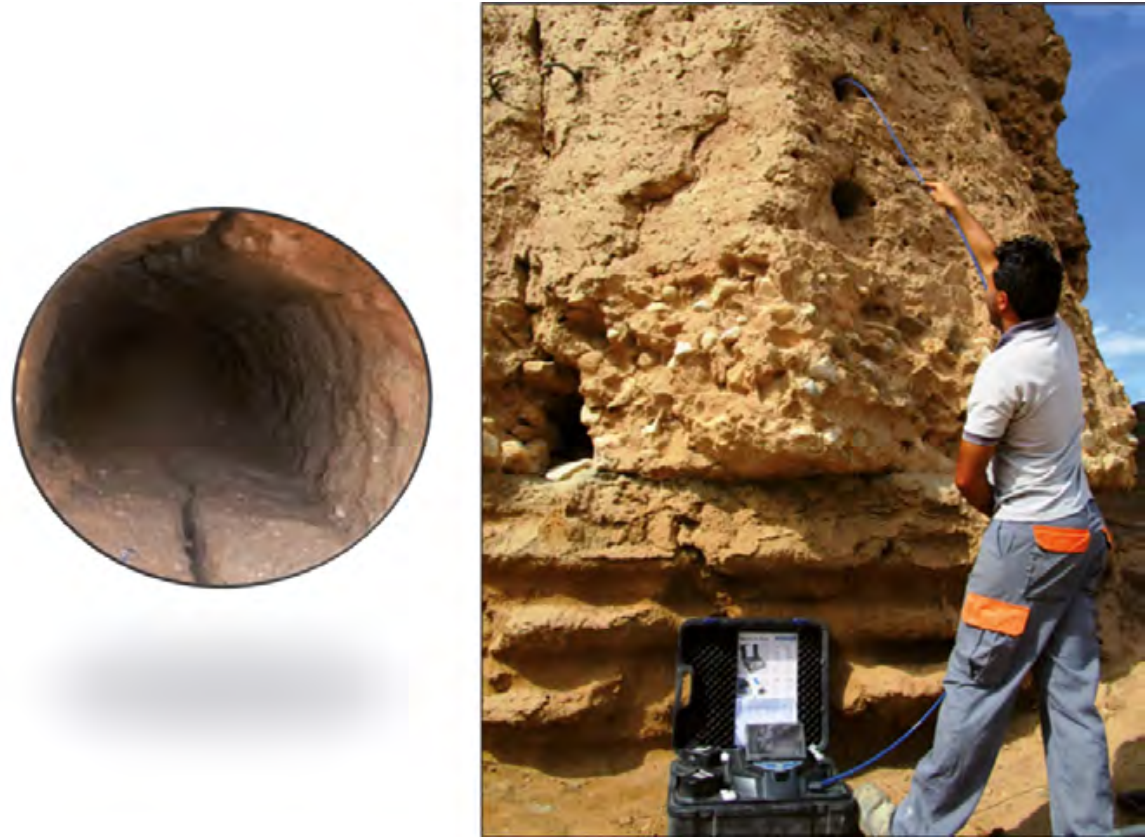

Figura 20. Inspección endoscópica.

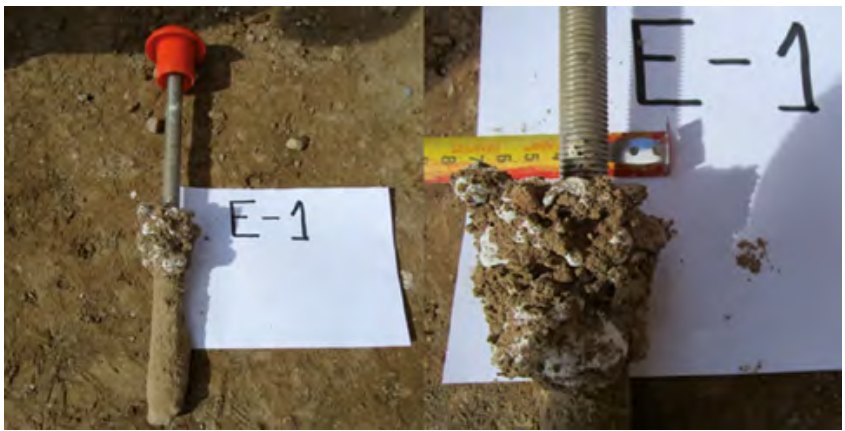

Figura 21. Ensayo E-1.

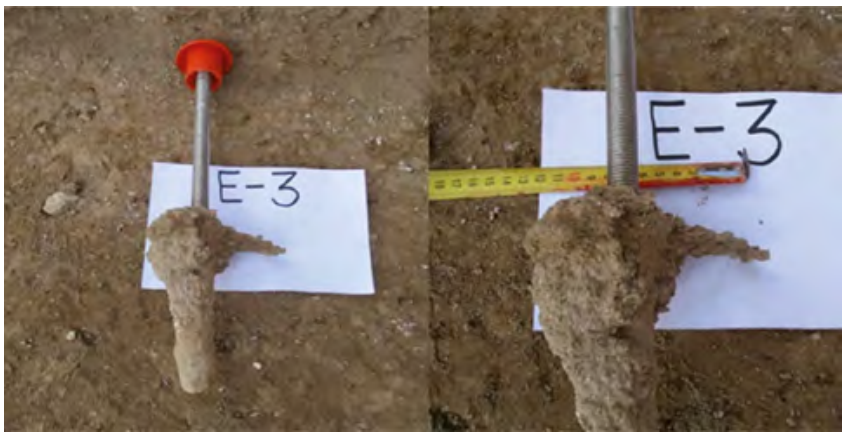

Figura 23. Ensayo E-3.

plazamientos del bloque de tapial), a la vez que se reparaban las discontinuidades existentes para dotar a la estructura de la torre de mayor monolitismo.

Los anclajes dispuestos, formados por un armado interior, una malla de poliéster que podía llegar a expandirse hasta un máximo del doble del diámetro inicial, y un mortero sin retracción ni expansión con una relación agua/cemento muy baja, funcionaban de la siguiente manera:

- En primer lugar, como anclaje químico, asegurando una adherencia admisible entre la mampostería y el mortero

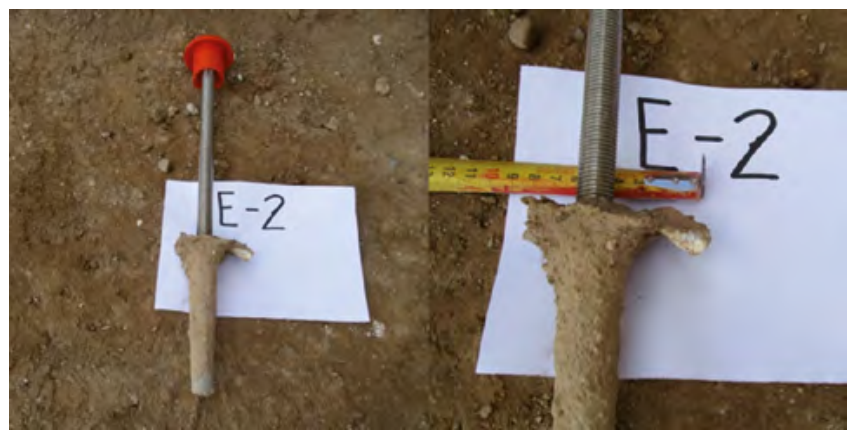

Figura 22. Ensayo E-2.

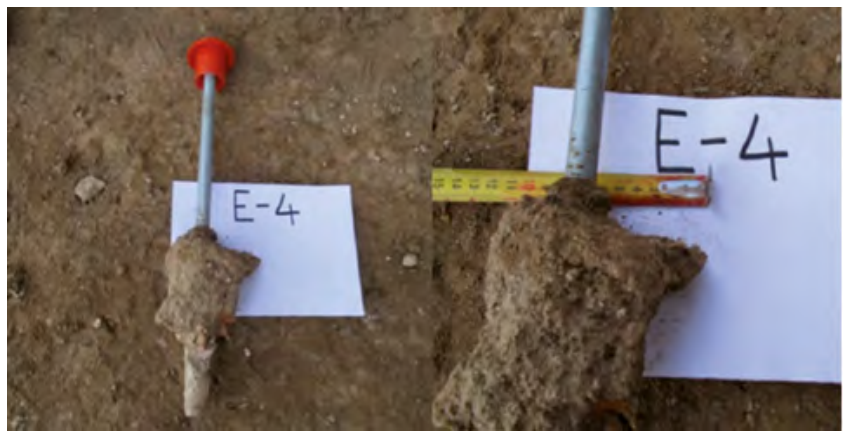

Figura 24. Ensayo E-4.

igual a $0.20 \mathrm{~N} / \mathrm{mm}^{2}$; en el caso del tapial la adherencia considerada era de $0.10 \mathrm{~N} / \mathrm{mm}^{2}$. Estos valores se han obtenido de ensayos realizados por los autores.

- Por rozamiento entre ambos materiales.

- Tercero, como anclaje mecánico, ya que al inyectar el mortero en el interior de la malla, esta se deformaría ajustándose a las irregularidades de las perforaciones, por lo que el resultado nunca es un cilindro perfecto en este tipo de muros. 


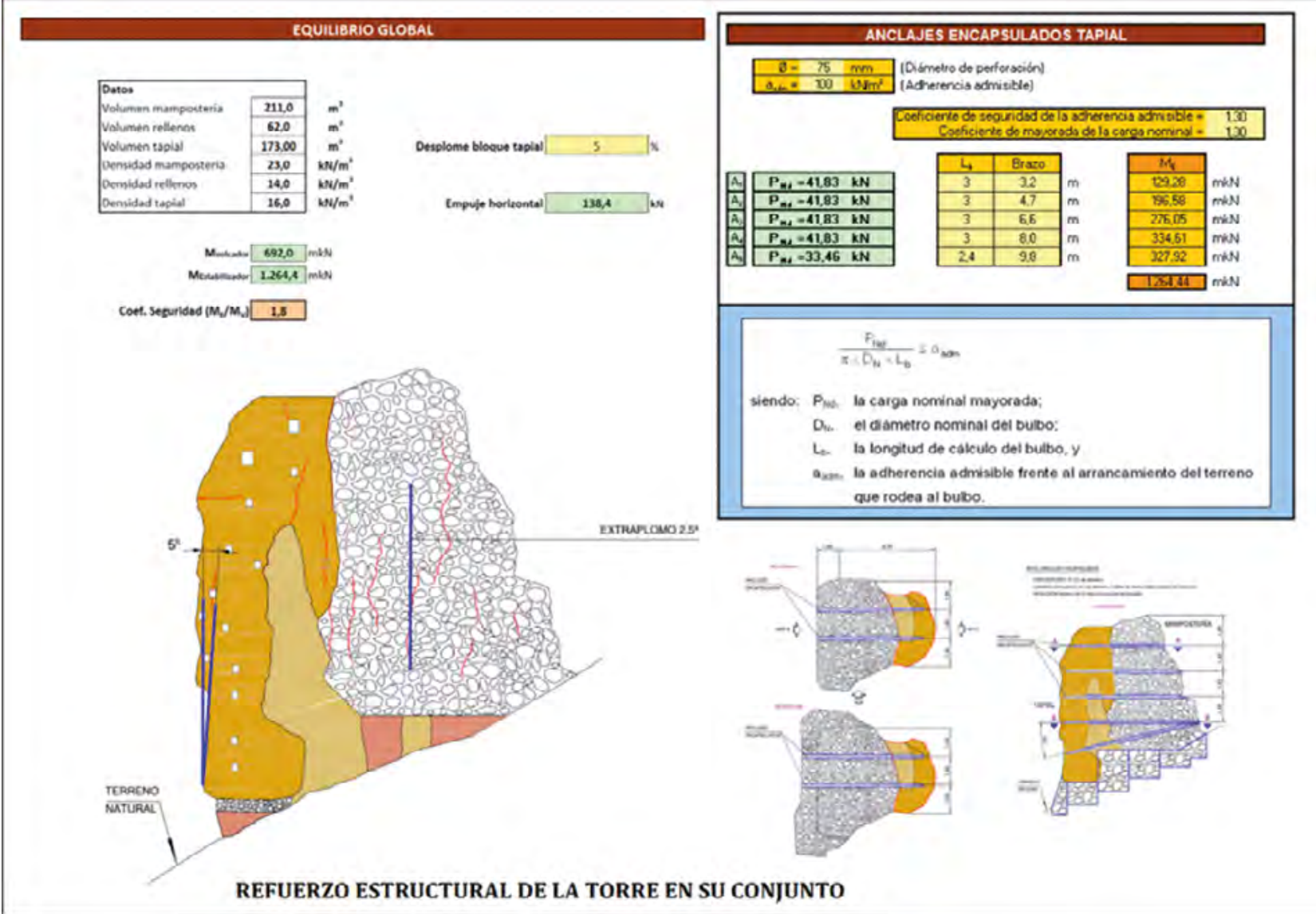

Figura 25. Diseño de la solución para la consolidación estructural.

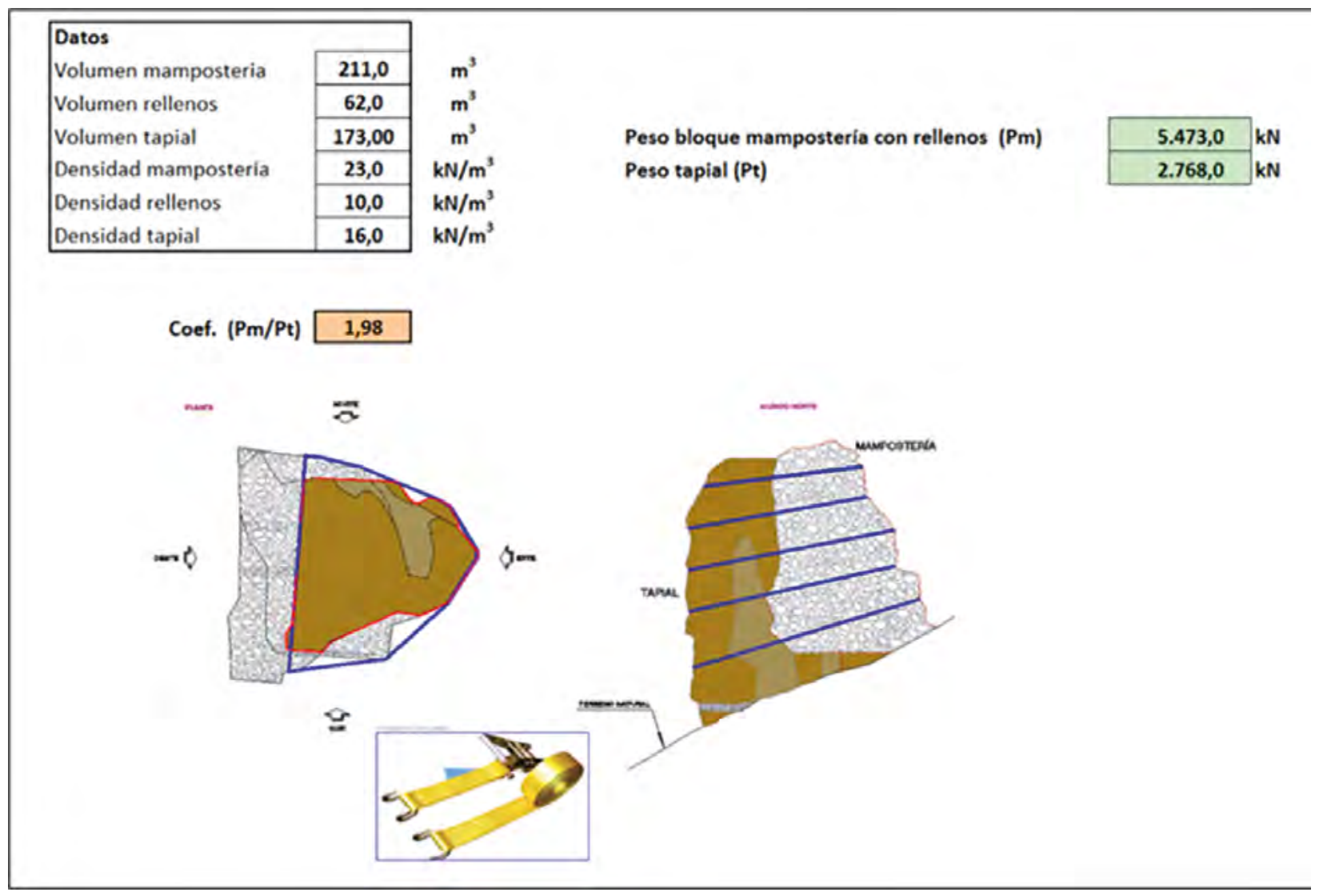

Figura 26. Evaluación del arriostramiento del bloque de tapial. 


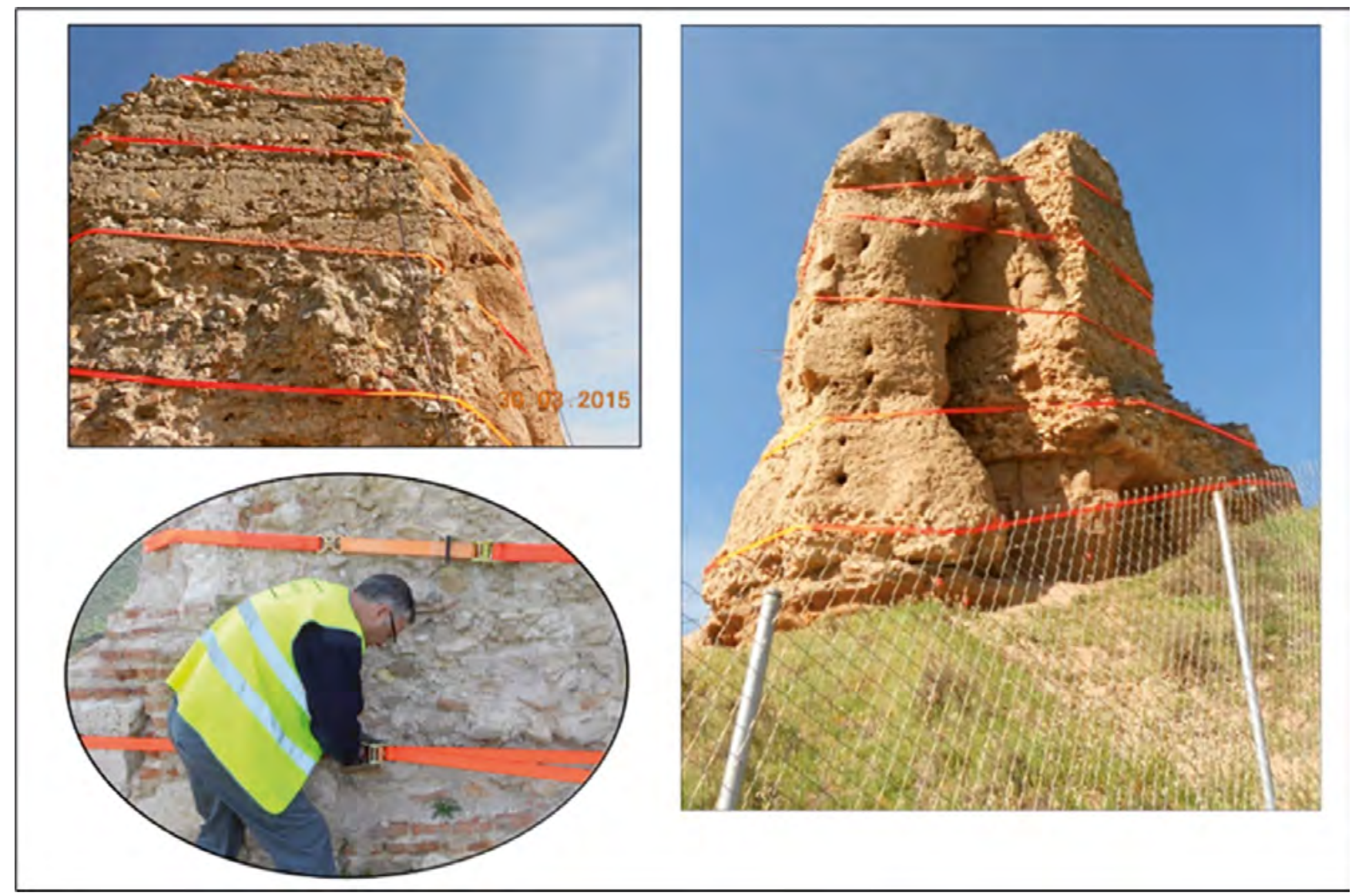

Figura 27. Montaje arriostramiento del bloque de tapial.

Este tipo de anclajes se calculó como si funcionaran únicamente por adherencia química, ya que es el caso más desfavorable de los tres anteriores, por lo que quedan del lado de la seguridad. Las longitudes de anclaje fueron determinadas en base a la geometría existente, estando condicionadas por las discontinuidades del paramento anterior.

Además, ante estructuras de este tipo en las que existe un cierto grado de indefinición de los materiales y técnicas constructivas, se utilizó un coeficiente de seguridad de minoración de la adherencia química admisible igual a 1.30 (este valor se ha obtenido de ensayos realizados por los autores en trabajos similares).

El cálculo se realizó evaluando los momentos de las fuerzas estabilizadoras (anclajes), frente a las que favorecen el vuelco (desplome del bloque de tapial). Ver figura 25.

\section{Fase $3^{a}$. Medidas preventivas antes de iniciar los trabajos}

Debido al estado que presentaba la torre, se consideró necesario proceder a realizar un arriostramiento de la parte construida en tapial, con el fin de evitar el vuelco. Como elemento de reacción se utilizó el bloque de mampostería, que sensiblemente es del orden de 2.3 veces más pesado (figura 26).

El material para efectuar el arriostramiento horizontal fueron eslingas textiles de alta capacidad (100 kN). No se pusieron en carga, únicamente se tensaron para mantener los planos de arriostramiento (figura 27).

\section{Fase $4^{a}$. Recalce de la cimentación por bataches}

El recalce por bancadas sobre el terreno natural se realizó con un hormigón ciclópeo de base cal. Este hormigón se realizó con piedra de la zona y colada de mortero fluido de base cal y puzolanas resistente a las sales, de tipo G según EN 998-2 [9] con aglomerante tipo NHL 3 y puzolanas, según EN 450-1 [10] (resistencia a compresión después de 28 días $>18\left(\mathrm{~N} / \mathrm{mm}^{2}\right)$.

El procedimiento constructivo fue el siguiente:

- Excavación de bataches según la definición mostrada en la figura 28.

- Saneo del sustrato erosionado.

- Relleno del batache con piedras a hueso, incluyendo inserción de barras de fibra de vidrio.

- Encofrado del batache.

- Vertido del mortero fluido de base cal.

- Picado de la capa superficial para dejar el aspecto de mampostería.

- Tintado con productos naturales.

En las figuras 29 y 30 se muestra la ejecución de esta fase de obra.

Una vez ejecutado el recalce de la cimentación mediante el sistema de bataches se procedió al relleno de los huecos (por colapso local del tapial) con adobes fabricados in situ con una formulación desarrollada por los autores con los materiales de la zona, basándose en citas de la referencia [8]. Ver figuras 31 y 32 . 


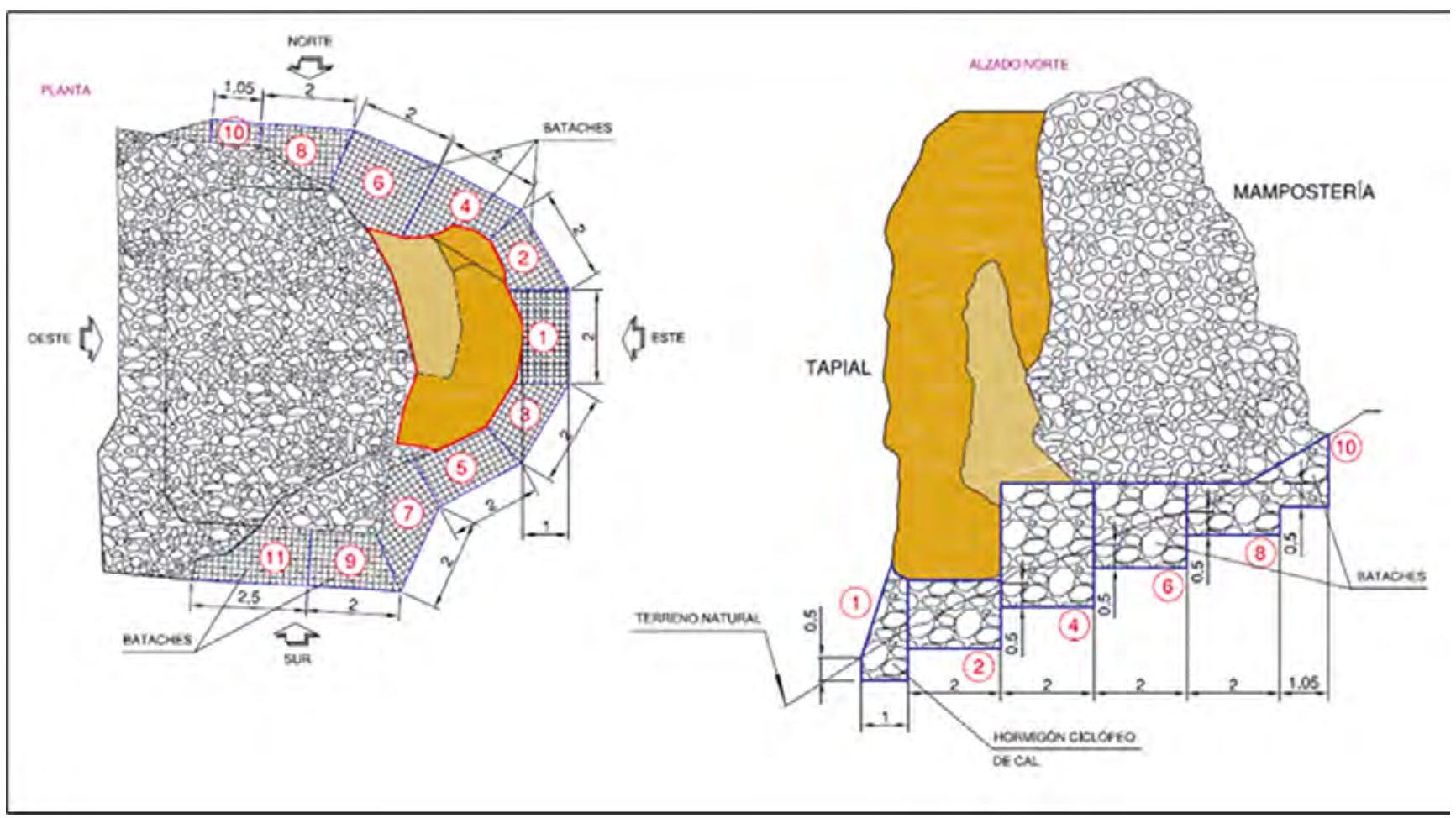

Figura 28. Definición de bataches.
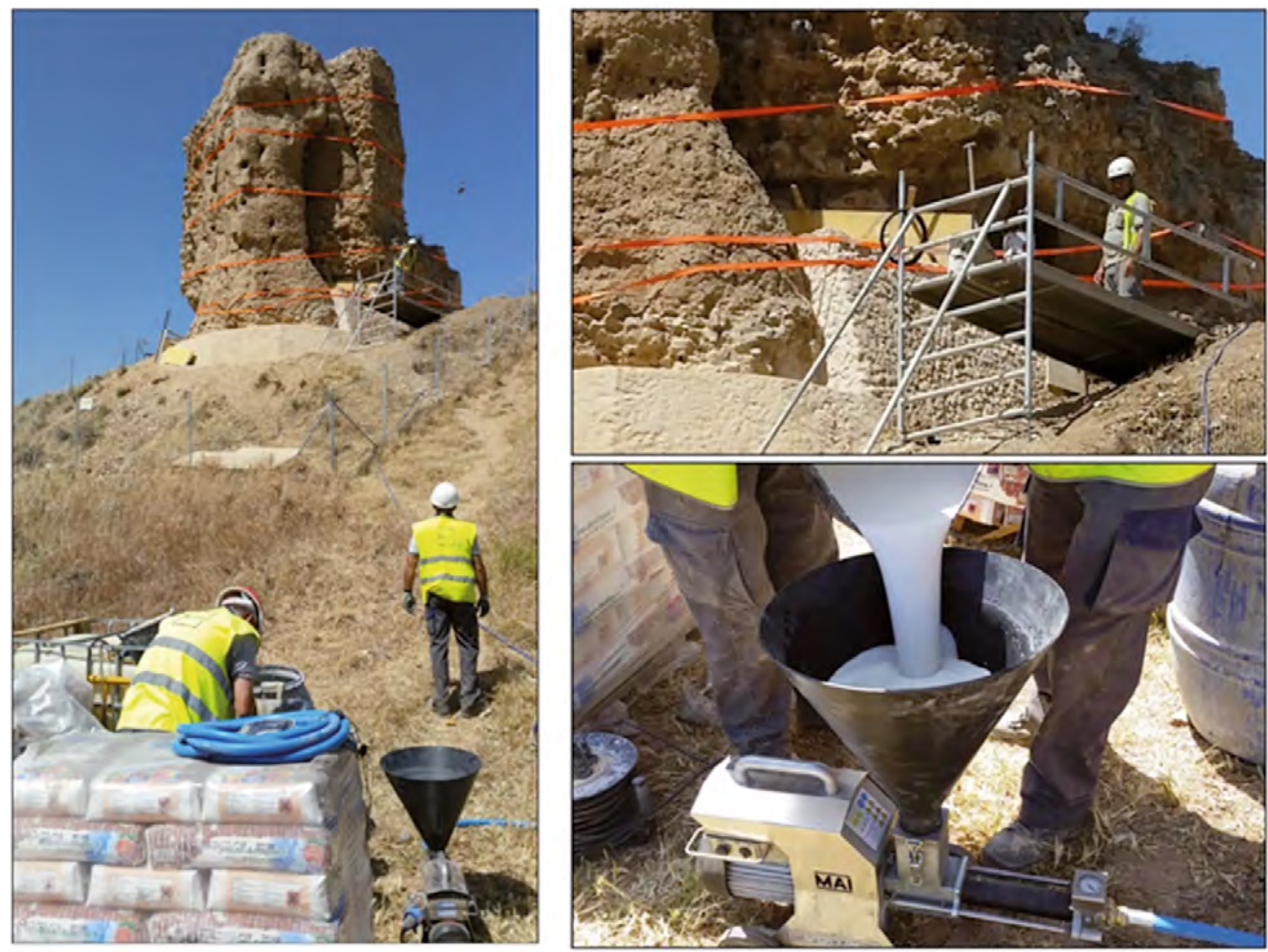

Figura 29. Ejecución recalce. 


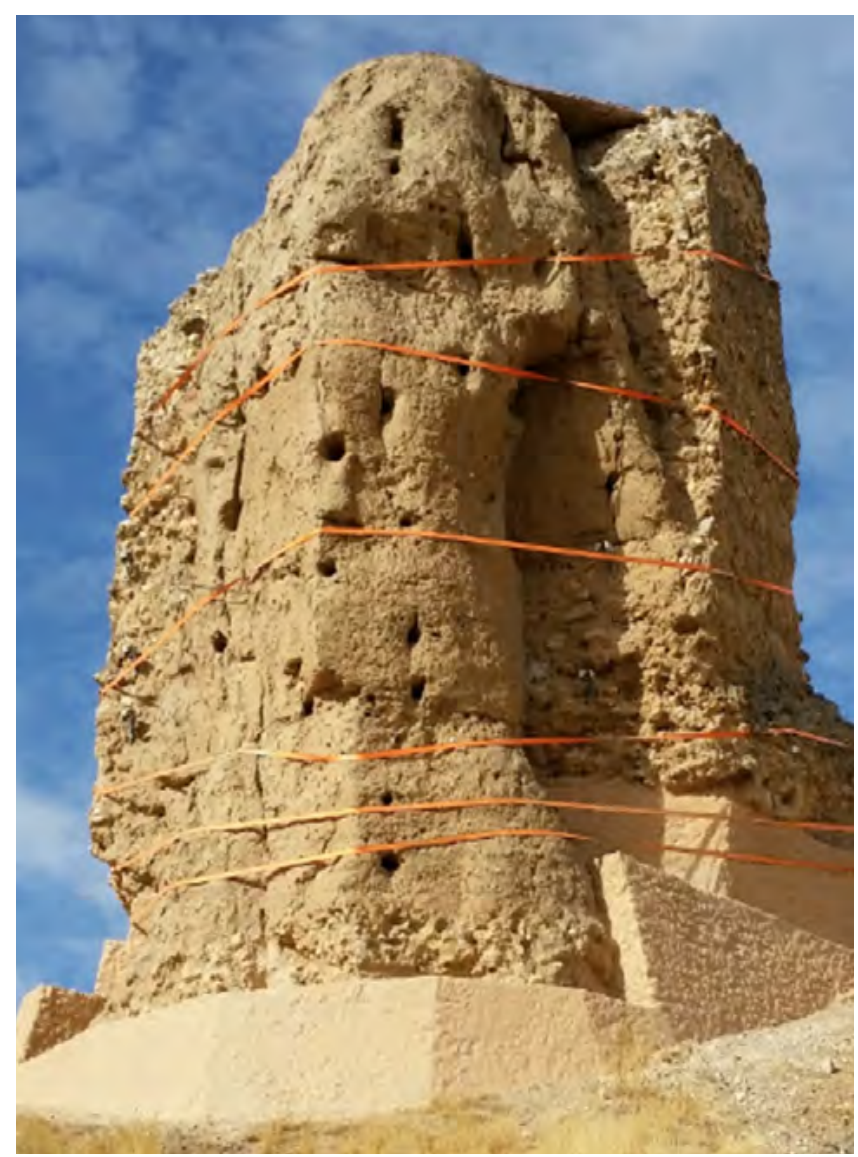

Figura 30. Aspecto final del recalce de la cimentación.

\section{Fase $5^{a}$. Consolidación estructural}

La consolidación de la torre se realizó mediante anclajes encapsulados (entre 6 y 14 m de longitud) según se ha comentado anteriormente.

El sistema de anclajes encapsulados está especialmente diseñado para el refuerzo de obras de fábrica. Debido a las características de estos elementos es posible dotar a los muros de arriostramiento transversal, así como de aumentar la capacidad portante de los mismos, sin cambiar su forma de trabajo.

Los anclajes se ejecutaron mediante perforación en los muros a consolidar, en los que se aloja propiamente el dispositivo de fijación. Este está compuesto por un corazón formado por una barra de acero inoxidable, que se recubre por una malla de poliéster que admite deformaciones máximas del $50 \%$ de su diámetro. El sistema consta además de tubos de inyección para rellenar las perforaciones desde el fondo hacia el exterior, utilizándose un mortero especial con altas prestaciones, sin retracción, de fraguado rápido, capaz de ser inyectado a baja presión.

La inyección quedaba confinada en el interior de la malla de poliéster deformable, dispuesta a lo largo de todo el elemento, que es capaz de adaptarse a las irregularidades de la perforación una vez rellena (inyectada).

La perforación para la instalación de los elementos de fijación se realizó mediante máquinas hidráulicas a rotación y con cabeza de corte formada por corona de diamante. Se perforó siempre a rotación, nunca a rotopercusión, de cara a evitar trasmitir vibraciones a una estructura debilitada.
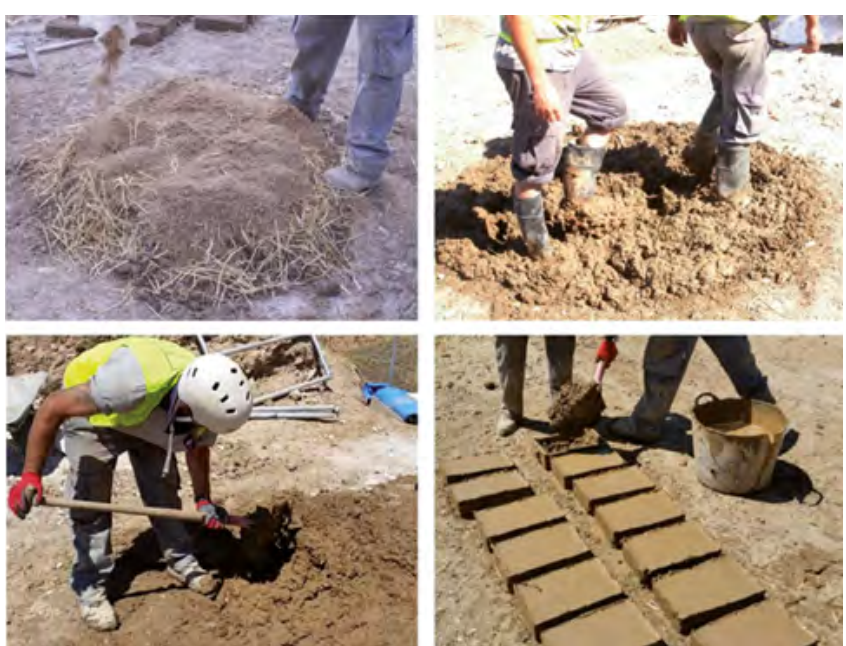

Figura 31. Fabricación de adobes.
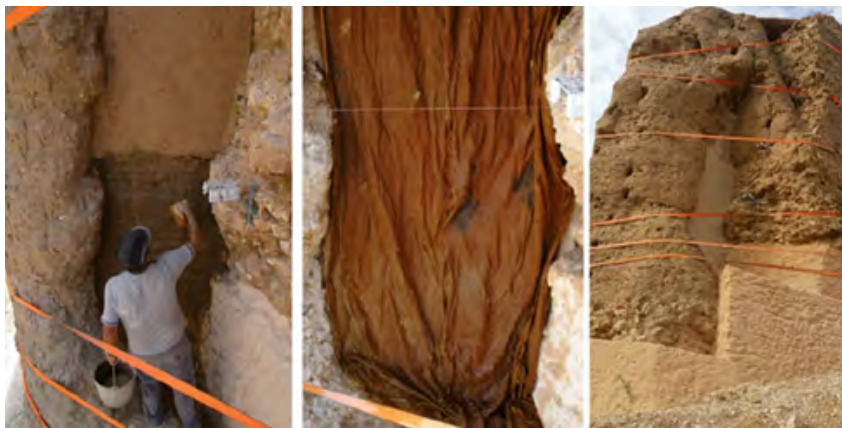

Figura 32. Puesta en obra de adobes, curado con arpilleras y acabado.

Una vez ejecutadas las perforaciones, se introdujeron las barras de armado interior, junto con la malla de poliéster y el tubo de inyección, y se inyectó a muy baja presión toda la longitud del elemento de fijación.

En las figuras 33, 34 y 35, se muestran los detalles de ejecución.

\section{Fase $6^{a}$. Tratamientos locales e hidráulicos.}

Una vez consolidada estructuralmente la torre se procedió al tratamiento local de las grietas y piezas sueltas, de acuerdo a los procedimientos que se indican a continuación:

\section{A) Cosido de grietas y piezas sueltas}

- Realización de perforación a rotación en seco atravesando el plano de fractura con un anclaje en soporte sano de $50 \mathrm{~cm}$.

- Limpieza del taladro con aire comprimido.

- Impregnación del interior del taladro con imprimación superfluida de una resina acrílica.

- Relleno del hueco de la perforación con una resina de viniléster híbrida sin estireno.

- Inserción de barra de fibra de vidrio de $12 \mathrm{~mm}$ de diámetro.

- Retirada de resina sobrante.

\section{B) Inyección de grietas}

- Retacado de grietas con mortero confeccionado con aglomerante hidráulico especial sin cemento con carga 


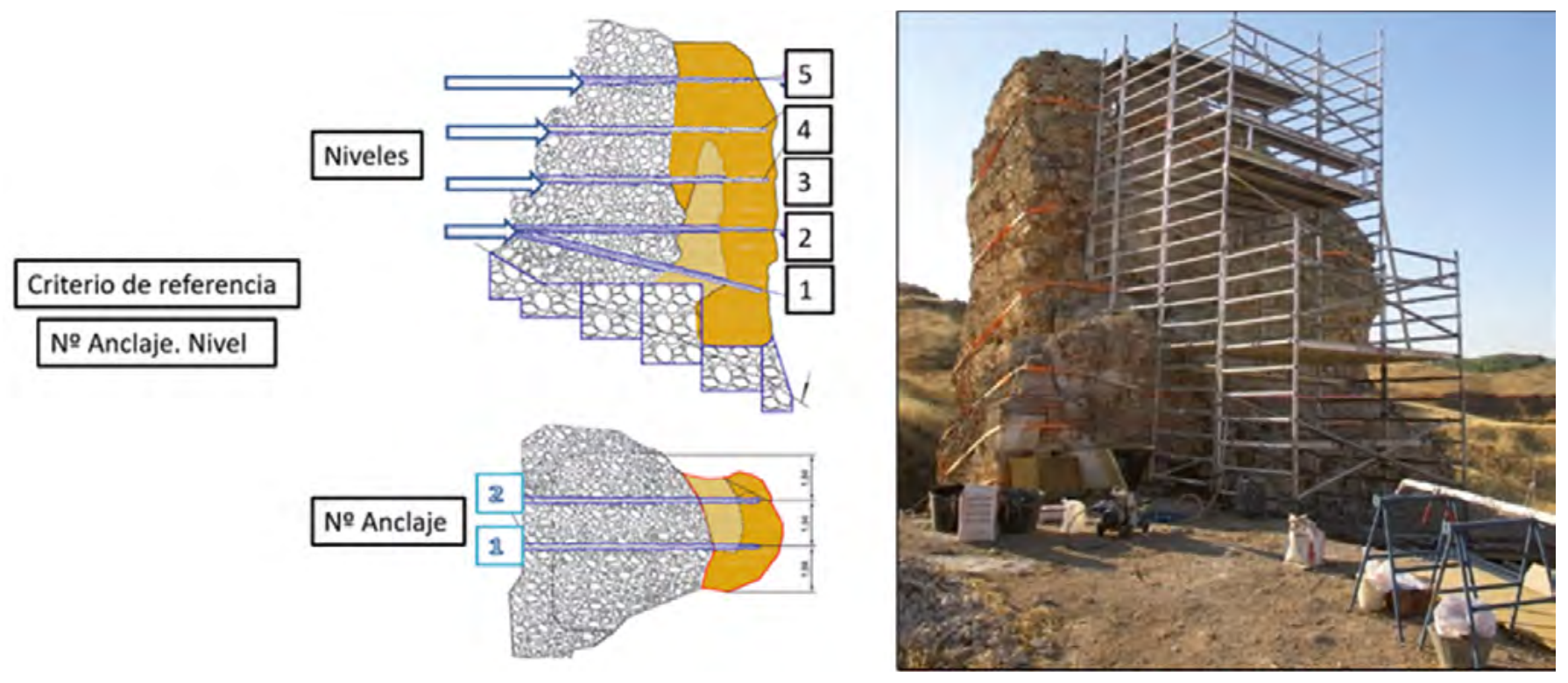

Figura 33. Replanteo de los anclajes y medios de acceso.
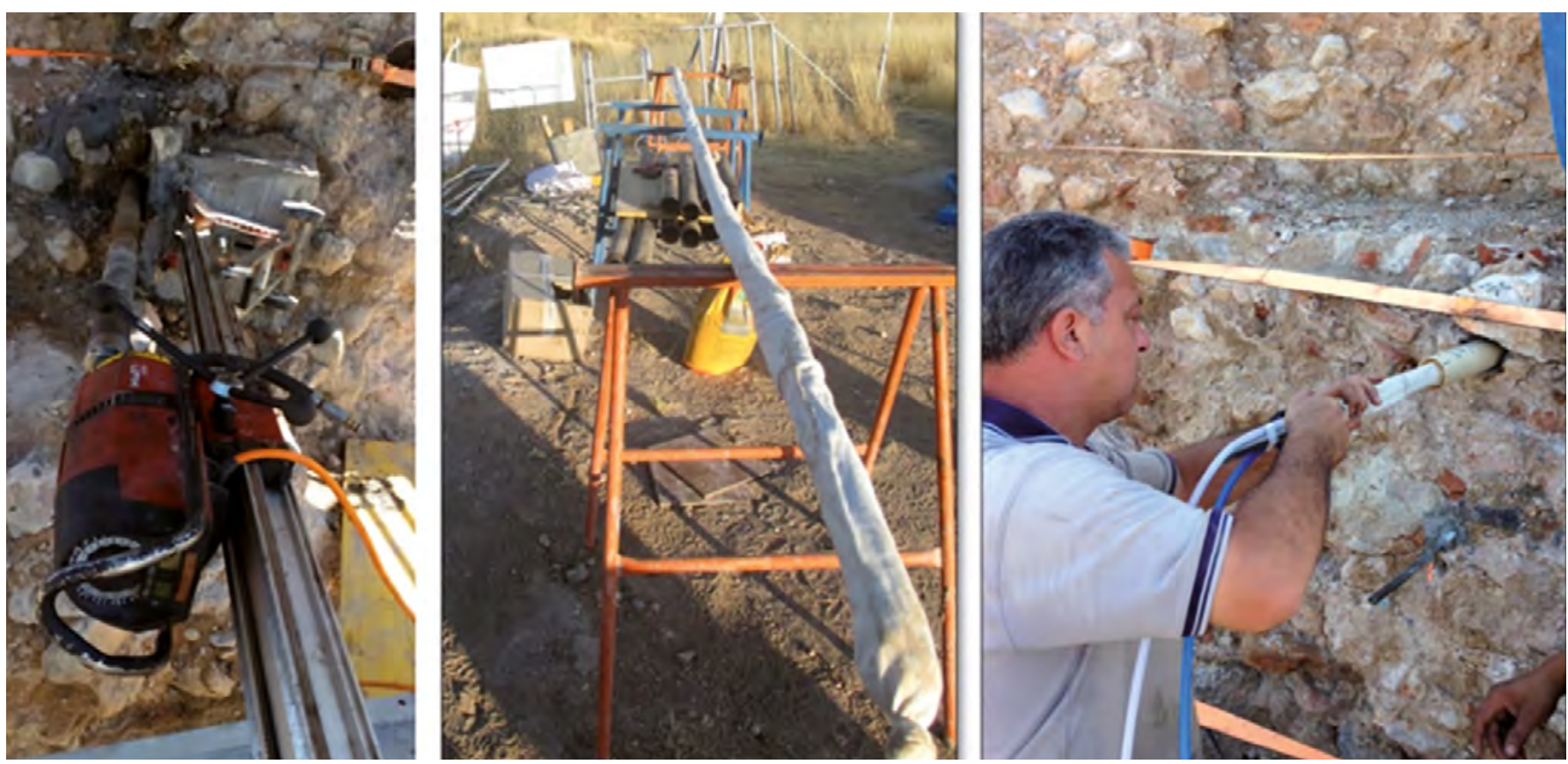

Figura 34. Perforación y montaje del anclaje.

mineral fina, mezclado con áridos locales con el fin de conseguir el mismo color que el soporte existente; en el momento de realizar el retacado se colocaron los inyectores.

- Inyección de ligante hidráulico con carga superfluida y libre de cemento de reacción puzolánica resistente a los sulfatos, previa saturación con resina acrílica.

En la figura 36 se muestran dichos trabajos.

Con objeto de evitar que las aguas de lluvia deterioraran la torre, se realizaron los siguientes trabajos:

- Impermeabilización de la cara superior de la torre con una capa de mortero de cal con un tratamiento hidrófugo.
- Construcción de un drenaje con una acera en todo el perímetro de la torre, con pendiente a favor del talud (ver figura 37).

En la figura 38 se muestra el resultado de la consolidación estructural de la torre.

\section{Conclusiones}

Estudiar al máximo para actuar lo mínimo es la manera correcta de entender la ingeniería de rehabilitación estructural, 

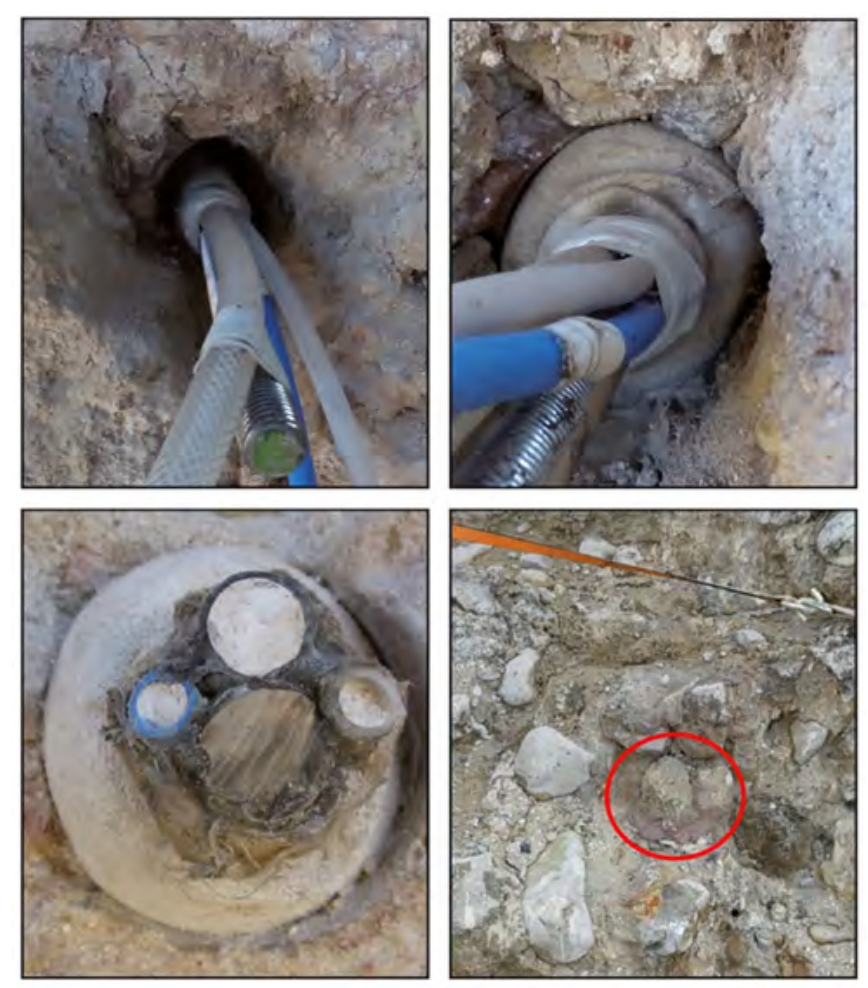

Figura 35. Proceso de inyección.

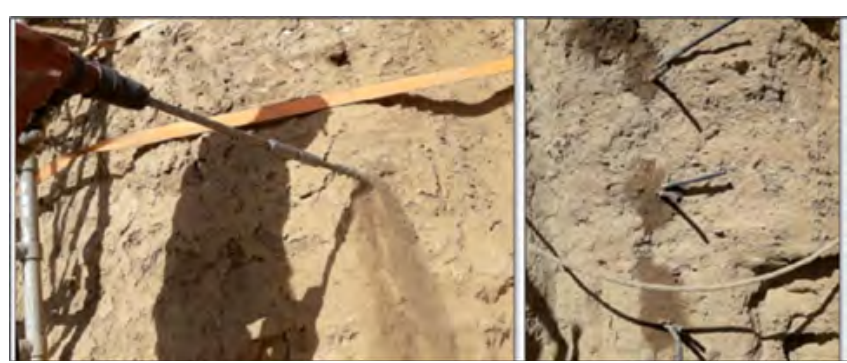

Figura 36. Tratamientos de grietas.
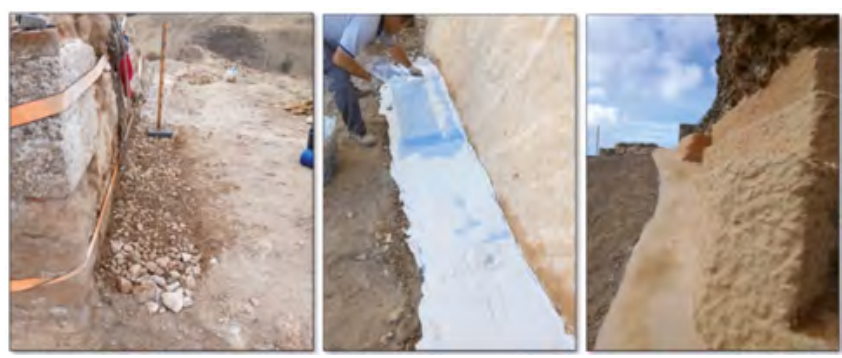

Figura 37. Ejecución de drenaje y acera perimetral en la torre.

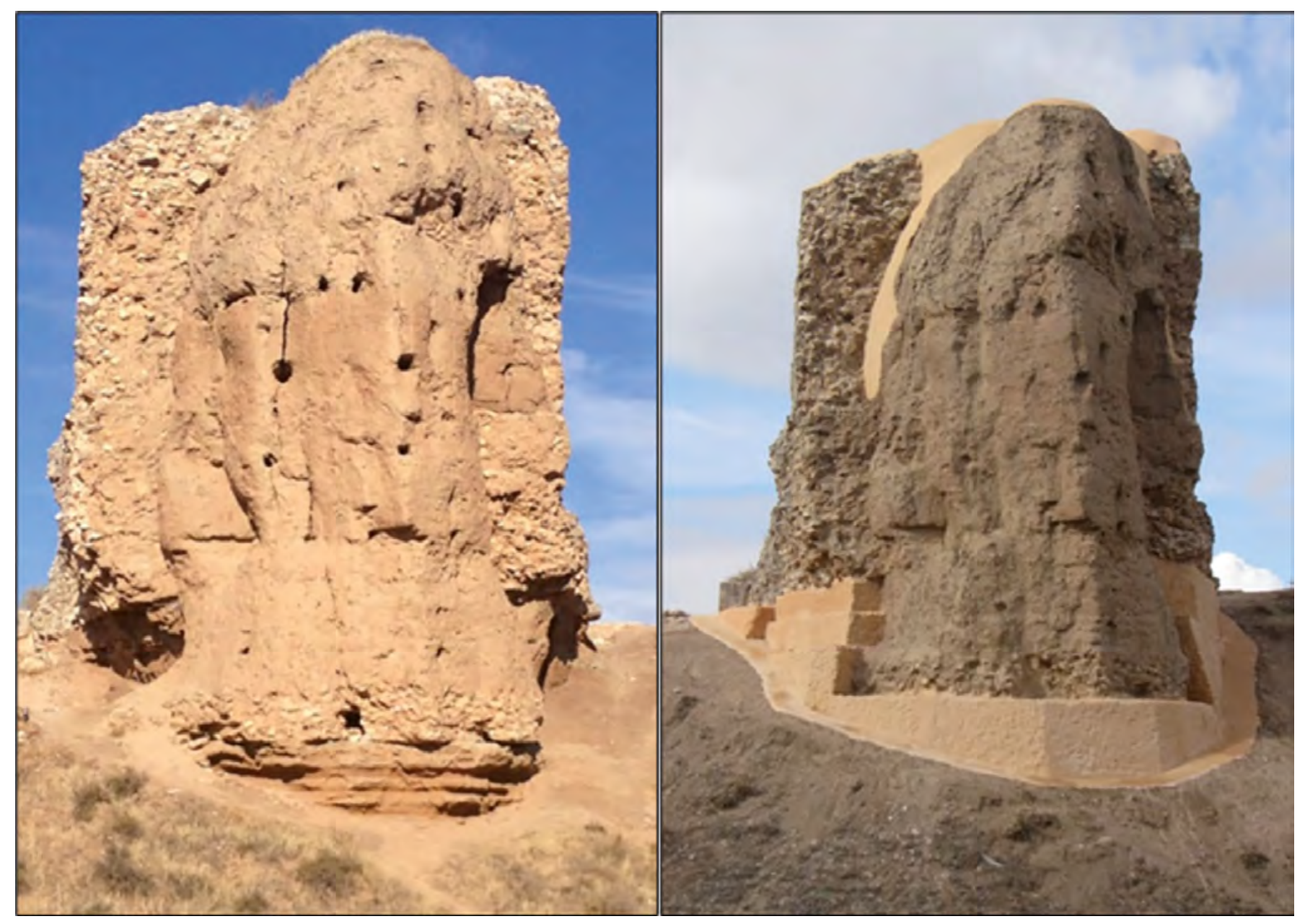

Figura 38. Estado inicial y final de la torre. 
con objeto de maximizar la eficiencia técnica y económica de cada intervención. Los dos ejemplos que se han descrito son totalmente diferentes en cuanto a su tipología, a sus procesos patológicos o antigüedad y, sin embargo, en ambos se ha aplicado la misma filosofía de trabajo.

Para que esta metodología tenga éxito es necesaria una trazabilidad y una calidad máxima en todo el proceso, desde los estudios previos hasta la ejecución de la obra. Por ello es muy importante realizar consorcios para que todos los agentes intervinientes colaboren desde la fase inicial.

\section{Agradecimientos}

Los autores de este artículo estaremos siempre agradecidos a Luis María Ortega Basagoiti, con el que hemos tenido la gran suerte de compartir más de 25 años como estrechos compañeros de trabajo. No solo hemos aprendido todos los días con él profesionalmente, sino sobre todo en el plano personal y humano. Era una gran persona y le echamos de menos todos los días. Descanse en paz.

\section{Referencias}

[1] Comisión Permanente del Hormigón (2008) Instrucción de Hormigón Estructural EHE-2008. Ministerio de Fomento. Madrid.

[2] SETRA (2007). Technical guide - Laminated elastomeric bearings use on bridges, viaducts and similar structures. Service d'études techniques des routes et autoroutes, 2007.

[3] Skempton, A.W., Macdonald, D.H. (1956). The allowable settlements of buildings. En: ICE Proceedings: Engineering Divisions, 5(6): 727-768. http://dx.doi.org/10.1680/ipeds.1956.12202

[4] Polshin, D.E., and Tokar, R.A. (1957). Maximum allowable non-uniform settlement of structures. En: On Soil Mechanics and Foundations Engineering, I, (pp. 402-405). London, England.

[5] Burland, J.B. (1977). Behavior of foundations and structures. State of the Art Report. En Proc. 9th Conf. On Soil Mechanics and Foundations Engineering, II, (pp. 495-546). Tokyo: Japanese Geotechnical Soc.

[6] National Coal Board (1975). Subsidence engineers handbook. National Coal Board Production Dept., London, England.

[7] Shadbolt, C.H. (1977). Mining subsidence - historical review and state of the art. In: Proc. Conf. Large Ground Movements and Structures, (pp. 705-748), Pen tech, London.

[8] Pavón Maldonado, B. (2012) Murallas de tapial, mamposteria, sillarejo y ladrillo en el islam occidental. http://www.basiliopavonmaldonado.es/Documentos/murallastapial.pdf.

[9] CEN. UNE EN 998-2:2018 Especificaciones de los morteros para albañilería. Parte 2: Morteros para albañilería. Asociación Española de Normalización. Madrid, 2018

[10] CEN. UNE EN 450-1:2013 Cenizas volantes para hormigón. Parte 1: Definiciones, especificaciones y criterios de conformidad. Asociación Española de Normalización. Madrid, 2018. 